\section{Alberto Donoso}

Anes

Departamento

de Contabilidad

y Economía Financiera.

Universidad de Sevilla
EL VIRREY DE LIMA: CABALLERO DE CROIX. DEFENSOR DE LA PARTIDA DOBLE EN EL SIGLO XVIII (*)

Resumen.-Palabras clave.-Abstract.-Key words.-1. Introducción.-

2. La derogación del nuevo método en la metrópolis.-3. Vuelta a la instrucción

de Landazuri de 3 de septiembre de 1767.-4. El defensor del nuevo método en Lima: El Caballero De Croix: 4.1. El Virrey, Caballero De Croix. 4.2. D. Teodoro De Croix, defensor de la Partida Doble.-Anexo.Bibliografía.-Documentación consultada.

\title{
RESUMEN
}

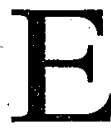

L trabajo que voy a detallar se centra en el debate: nuevo método (partida doble) versus antiguo método (cargo y data), que surgió en el seno del funcionariado tras la derogación, en la península (metrópolis), de la aplicación del método de la partida doble para llevar las cuentas públicas de Indias, aprobado en 1784. Convirtiéndose en una de las polémicas del siglo xvIII que más tinta derramó en honor y defensa del Arte de la Partida Doble.

(*) Este trabajo forma parte de una investigación más amplia, financiada por el proyecto de investigación «Cambio Contable y Cambio Organizativo» (PB-96-1353). 
Proceso de derogación que, aunque se inició en la península, su onda expansiva se dejó sentir en los dominios de ultramar. En las Indias, tras la derogación se dieron encendidos debates, siendo el caso del Perú el que más ha llamado nuestra atención por la racionalidad, constancia y fortaleza que mostró en todo momento su Virrey, Teodoro De Croix, quien llegó a tener duros enfrentamientos con algunos de los empleados de la Real Hacienda de Indias, tal y como veremos a continuación.

\section{PALABRAS CLAVE}

Historia de la Contabilidad; Partida Doble.

\section{ABSTRACT}

The piece of research we present is focused on the debate: new method (double entry) versus old method, that arised within the civil functionaries, after the derogation in 1784 of the application of the double entry method for the colonial governmental accounting. This was one of the most polemical controversies around double entry in the XVIIIth century.

Although this process begun on the mother country, the effects stroke the overseas colonies. In America (the Indias), after the derogation passionated debates were manteined. The case most strongly has raised our attention was Perú, because of the level of racionality, firmness and vigour held by the Virrey, Teodoro De Croix, who manteined hard argues with some employees of the Royal Treasure of Indias.

\section{KEY WORDS}

Accounting History; Double-Entry Bookkeeping. 


\section{INTRODUCCIÓN}

El relato que queremos dar a conocer, se sitúa en el marco de reformas que se llevaron a cabo en las Indias en el siglo XvIII, en el período que cubre los últimos veinte años, y concretamente se trata de una reforma contable (1), como era la aplicación de la partida doble para llevar las cuentas de las instituciones públicas y, particularmente, en las Cajas Reales de Indias.

El trabajo que voy a detallar se centra en el debate que surgió en el seno del funcionariado: nuevo método (partida doble) versus antiguo método (cargo y data). Ya que las dos últimas décadas del siglo xvIII las podríamos considerar como aquellas en las que más tinta se derramó en honor y defensa del Arte de la Partida Doble. Situación que finalizó con la derogación de la Instrucción (2) que permitió por primera vez la aplicación de la partida doble en las Cajas Reales de Indias.

En el Archivo General de Indias encontramos todos los informes relativos al proceso de derogación del método de Partida Doble aprobado, en 1784. Proceso que, aunque se inició en la península, su onda expansiva se dejó sentir en los dominios de ultramar. En las Indias, tras la derogación se dieron encendidas polémicas, siendo el caso del Perú el que más ha llamado nuestra atención por la racionalidad, constancia y fortaleza que mostró en todo momento su Virrey, Teodoro De Croix (3), quien llegó a tener duros enfrentamientos con algunos de los empleados de la Real Hacienda de Indias, tal y como veremos a continuación.

(1) Todo lo referente a dicha reforma, incluido el proceso de implantación y derogación puede consultarse; Donoso A.: «Estudio histórico de un intento de reforma en la Contabilidad Pública: La aplicación del Método de la Partida Doble en las Cajas Reales de Indias (1784-1787)", Revista Española de Financiación y Contabilidad, vol. XXVI, núm. 93, pp. 1045-1089.

(2) El desarrollo y comentarios sobre la misma se pueden encontrar en Dovoso, A.: "Nuevo método de cuenta y razón para la Real Hacienda en las Indias: La Instrucción Práctica y Provisional en forma de Advertencias Comentada (27 de abril de 1784)", Revista Española de Financiación y Contabilidad, vol. XXVIII, núm. 101, julio-septiembre de 1999, pp. 817-862.

(3) Ya Ramos Cerveró, en el Encuentro de Trabajo de «La Cristalera» (1992), puso de manifiesto tal acontecimiento resaltando, de forma especial, la figura del Virrey De Croix, por la defensa que realizó sobre la aplicación del método de la partida doble en las cuentas públicas; publicado posteriormente por AECA (1996). 


\section{LA DEROGACIÓN DEL NUEVO MÉTODO EN LA METRÓPOLIS}

D. José de Gálvez, Ministro de Indias y principal propulsor de las reformas indianas, moría el 17 de junio de 1787 (4). El fallecimiento de Gálvez no sólo supuso la paralización de todo un proyecto, sino también un triunfo para los conservadores que, alarmados por el ímpetu de las reformas que se sucedieron en Ultramar en los últimos años de su mandato, debieron descansar tras la paralización repentina y derogación de algunas medidas clave ya impuestas, como fue el rechazo de la Instrucción de 1784 sobre la aplicación del método de la partida doble y cuyo responsable directo era el Contador General de Indias, D. Francisco Xavier Machado Fiesco; y el restablecimiento, como consecuencia, del método antiguo de cargo y data, volviendo a la Instrucción que su antecesor D. Thomas Ortiz de Landazuri daba el 3 de septiembre de 1767.

Llegados a esta situación y ante la duda de la efectividad de la implantación del Nuevo Método, tomando como únicos argumentos la reducción del trabajo y de los costes de personal, el nuevo ministro D. Antonio Valdés solicitaría informes, por la Vía Reservada (5), sobre la bondad del método de partida doble. En concreto pedía, a un consejo de expertos, que argumentasen si el método de partida doble era más exacto, más breve y seguro; y.más conforme a la buena administración de los reales intereses que el de cargo y data. Las personas que participaron en dicho consejo y emitieron los informes correspondientes fueron:

- D. Josef García de León y Pizarro: Ministro Togado del Consejo de Indias, que había sido Presidente y Visitador de Quito.

- D. Manuel Ignacio Fernández: Ministro de Capa y Espada del mismo Tribunal e Intendente de Buenos Aires con anterioridad.

(4) Luis Navarro Garcia: Intendencias en Indias, Sevilla 1959, p. 115.

(5) Unos de los canales de comunicación que los Secretarios mantenían con las autoridades y funcionarios de las Indias, tenía un carácter reservado, haciendo de la Secretaría lo que Bermejo J. L. [1982, p. 35] califica como el centro de información político-administrativo mejor dotado de la Monarquía. La Vía Reservada no tuvo competencias claramente establecidas hasta 1717, a partir de esta fecha, constituyó un canal de comunicación directo con la Secretaría que, a su vez, informaba al monarca. La Secretaría antes de pasar a informar al monarca, podía solicitar informes especializados al Consejo de Indias; que en materia de cuentas sería la Contaduría General del Consejo de Indias la que elaboraría dichos informes. Durante el mandato de Francisco Machado, se llegó a crear una oficina apartada de la Contaduría para realizar este tipo de actividades. Para estas tareas tenía un personal cualificado y con dedicación exclusiva como fueron Sebastián de Jócano y Madaria y Pedro Carranza. 
- D. Joaquín Gutiérrez de Rubalcaba: Intendente de Marina del Departamento de Cádiz.

- D. Pedro Carranza: Oficial de la Contaduría General de Indias y subordinado directo del Contador General, que trabajaba junto con Sebastián de Jócano y Madaria en los asuntos de la Vía Reservada (6).

En realidad, los informes dados por estos señores se limitaban a reafirmar las objeciones que en su día, había recogido el Barón de Bielfeld (1762) en su obra:

"Aunque esta invención, debida a los italianos, es excelente para el comercio de los particulares, no la considero adaptable a las Rentạs Públicas, porque duplica el trabajo del que lleva las cuentas, porque son pocos los instruidos en ellas y porque el continuo paso y traslado que se hace de las partidas de un libro a otro, puede ser ocasión de muchas omisiones y de muchos errores de cálculo. Mejor es según mi dictamen apelar al simple método de Cargo y Data de que esta enterado qualesquiera que sabe contar y de que dependen las operaciones más sencillas de la aritmética» (7).

Todos esos informes se enviaron al Ministro de Indias Antonio Valdés, que recogiendo, de forma sintética, cada uno de los puntos mencionados en ellos, y en especial, las propuestas que Carranza establecía en su primer informe; derogaba, por Real Decreto (8) de 25 de octubre de 1787, la Real Cédula que aprobó la partida doble.

Entre las causas alegadas para el establecimiento, nuevamente, del método de Cargo y Data, que recogía este R.D. destacamos las siguientes:

(6) En un oficio dirigido a Gálvez, en el que Machado mostraba el apoyo a D. Pedro Carranza, para conseguir su permanencia en la Contaduría General. Hacía un comentario sobre el papel que desempeña dicho contador en la oficina. "y sabe V.E. también que, como uno de las más sobresalientes en todas lineas, le tengo con D. Sebastián de Jócano, oficial octavo, y acuerdo de V.E., destinado a trabajar en la Oficina que he puesto en mi casa para el despacho de todos los expedientes que se me pasan de esa Vía Reservada, y de algunos de los que corren por el Consejo que por su gravedad piden mas serio exâmen». A.G.I. Sección Indiferente General 1009.

(7) Nosotros hemos corroborado esta cita consultando la obra del Barón de Bielfeld, de la cual existen dos ejemplares en la Biblioteca Colombina. Esta obra debió despertar un gran interés en nuestro país, lo que pone de manifiesto el propio traductor en su dedicatoria al Conde de Aranda: "La obra que tengo el honor de publicar a la sombra de V.E. la han considerado hombres grandes única en su especie, y capaz de producir una utilidad general a la monarquía, cuyo bien estar y lucimiento forma el objeto y los afanes de V.E. que los tomará España por época memorable de sus felicidades.»

(8) A.G.I. Sección Indiferente General, legajo 662. 
- No conseguir el fin previsto con la implantación del nuevo método, debido a:

- Fưerte oposición a las prácticas nuevas.

- Poca formación de los Subalternos y Amanuenses.

- La dificultad de llevar a la práctica por personas que no se habían formado en las casas de comercio.

- Debía ser un método inteligible a todos, incluidos los Ministros de los Tribunales de Cuentas, que debían auditarlas conforme a las Leyes de Indias.

- Necesidad y ventajas que se derivaban, de la aplicación del mismo método que en España. Demandaban uniformidad.

- La dificultad de llevar a cabo la implantación "por personas que carecían de la instrucción, talento y demás recomendables cualidades, que concurren en su Autor».

Tal suceso se comunicó a Francisco Machado, el 31 de octubre de 1787 (9), adjuntándo a dicha comunicación una carta "confidencial», cuyo texto íntegro transcribimos a continuación, dado su indudable interés histórico contable:

«Mui Sor.mio. No puedo mirar sino como una advertencia amistosa el papel de V.S. de ayer acerca de la variación del método de cuenta y razón de Indias restableciendo el antiguo de cargo y data, y en el mismo estilo digo á V.S. que mi obligación me induce a mirar con particular interés por el deçoro del Rei y el honor de mis Subalternos: ni uno ni otro se aventuran en lo que S.M. ha resuelto, y si como está persuadido y satisfho de la inteligencia y zelo de V.S. lo estuviese de todos los Dependientes de las oficina de Indias, y de los Contadores interventores que por desgracia carecen de ella no habria sido necesaria la alteración resulta: no ha creído S.M. preciso oír a V.S. nuevamente para verificarla, asi porque ya expuso quanto creyó conveniente para el establecimiento de la partida doble, como por el antiguo método está canonizado por todos los Tribunales de Cuentas, y se sigue constantemente en España.

En esta sincera contextacion que hago al Papel de V.S. de que no haré uso de oficio porque temería desagradar á S.M. conocerá V.S. la estimación que' hago de su merito, y la prueba que quiero darle de que hablo siempre con el corazón en las manos: que no cabe en mi modo de pensar hacer nada con otro fin que el del mejor servicio del Rei, y esperando se conducirá del mismo modo por efecto de su

(9) A.G.I. Sección Indiferente General, legajo 1706: 
honrradez y zelo, no tendremos en que tropezar, y será siempre de V.S. su afecto servidor y Amigo.»

Esta carta nos desvela algunos aspectos importantes, el primero de ellos es que en ningún momento se tuvo en cuenta la opinión de Machado, principal responsable e interesado en dicha materia, llevándose a cabo la derogación de forma obscura y sólo pidiendo informes a cuatro personas, sobre un asunto tan importante y delicado como eran las cuentas de la Real Hacienda. Y por otro lado, este documento parece ser la contestación a un escrito (10) anterior, del Contador General, donde éste debió expresar, sus sentimientos e impotencia sin ningún tipo de reservas, cuando a lo largo del documento se exponía: "No puedo mirar sino como una advertencia amistosa el papel de V.S. de ayer acerca...", "no haré uso de oficio...», donde nos da a entender que debieron ser palabras muy duras. Evidentemente esta carta, más que ser conciliadora, se convertía en una invitación al Contador General para que no moviera proceso alguno que paralizara tal decisión, y dejara las cosas tal y como estaban.

Francisco Machado debió de quedar sorprendido al recibir la noticia y descubrir que uno de los impulsores del fatal cambio fue alguien en quien había depositado su máxima confianza: D. Pedro Carranza (11), quedando, desde entonces, sumido en un silencio que duraría casi un año. Fue el 4 de septiembre de 1788 (12), tras meditar los perniciosos

(10) Desconocemos el contenido de este documento ya que no ha sido posible su localización.

(11) A.G.I. Sección Indiferente General 1009. Oficio del Contador General a D. Josef de Gálvez, en 28 de julio de 1781 .

En ese documento se muestra la confianza y apoyo que depositó D. Francisco Machado en D. Pedro Carranza. En él, se hace referencia a una gran pérdida, de una persona tan valiosa - por la marcha de D. Pedro Carranza-, pues se le había propuesto la Secretaría de la Presidencia de Castilla. Antes de tomar una decisión, consulta a su jefe, expresándole la necesidad que tenía por la carga familiar - mujer y cinco hijos - no queriendo perder esa oportunidad, pese al cariño que tiene a la Contaduría. Machado, ante tal pérdida, comunicaba la situación a Gálvez, en defensa de su permanencia én la Contaduría General, pese a la difícil situación económica por la que estaban pasando, el ministro de las Indias, le concedía una dotación de 9.000 reales procedentes del uno por ciento de la plata que viene de Indias que se cobra y distribuye a disposición del ministro, como gasto secreto del servicio.

(12) «El Contador General: Representa las dificultades que impiden revisar las cuentas de Indias con la sencillez que expresa la Real Orden que se le pasó en 31 de octubre, del año próximo anterior. $Y$ los defectuosos fundamentos en que se apoya la Real Orden circular de 25, del mismo mes comunicada á Indias sobre la cuenta y razón, y: Pide: que el asunto se exâmine como lo exige su mucha importancia», A.G.I. Sección Indiferente General, 1712 . 
efectos que tendría sobre la Real Hacienda el decreto de 25 de octubre de 1787; lo que le llevó a enviar un informe a D. Antonio Valdés. El principal motivo, que le impulsó a realizar dicho escrito, fue el sentimiento de culpabilidad que tenía por no haber reaccionado a tiempo, y con la misma intensidad con que lo defendió al principio, dejando a los Oficiales Reales y a los intereses de la Real Hacienda expuestos a un método sin reglas, y a las injustas sanciones que sobre ellos recaerían como consecuencia de tal confusión.

«..., no descubro respecto á mí sino los mas urgentes cargos contra mi silencio. El decoro y esencia de mi empleo, el honor, los intereses y las fortunas de los Oficiales Reales Ministros de la Real Hacienda de Indias y principalmente el servicio del Rei y su justicia, todo se ve interesado y comprometido en la resolución tomada y comunicada en la referida $\mathrm{R}$. Orden circular - en referencia a la R.O. de 25 de octubre de 1787-, y creo de mi precisa obligación mirar por todos estos tan justos respectos en el caso en que se hallan. Por tanto, deseando ponerlos á cubierto de las resultas, y no quedar yo para la posteridad con la nota de un culpable silencio en mi Oficio, ...».

"¿Cómo es posible que vivan con sosiego unos Ministros -en referencia a los Oficiales Reales- cuya honra , interes y fortuna están vendidos y pendientes de unas cuentas llevadas sin método? ¿Con qué justicia se puede proceder contra ellos, y contra sus Fiadores, con el duro rigor de las Leyes fiscales por el mero hecho de discordar los asientos de sus libros con las efectivas existencias, no habiéndoseles exigido suficiencia para nombrarlos ni dádoseles instrucción para llevar sus cuentas.»

Al recibir Valdés el escrito de Machado, el 16 de octubre de 1788, lo remitiría a Pedro Carranza para que dictaminase y poder tomar una decisión. Carranza accedió a tal petición entregando un informe, acompañado de una carta donde exprésaba la situación, a la que le había llevado este asuinto en su relación personal con Francisco Machado, ya que éste se había enterado de su participación en un informe anterior (13):

"Suplico humildemente a V.E. se sirva estrechar sus ordenes para la reserva de este asunto, pues hace un año, que estoi padeciendo mucho en mi espíritu y salud por haberse llegado a entender mi anterior concurrencia en él.» 
Todo este proceso daba a entender que Valdés por un lado había encontrado un gran apoyo, en la persona de Pedro Carranza, para llevar a cabo su política de rechazo a las reformas, y por otro lado parecía que quería enfrentar a ambos minando las relaciones personales. Tras este informe no tenemos más constancia de lo acaecido en España sobre esta materia.

Sin embargo, sería con el transcurso del tiempo y más concretamente en 1793, cuando un subalterno de Machado y hombre de su confianza en dicha Contaduría, D. Sebastián de Jócano y Madaria (14) publicaba una obra con el siguiente título: Disertación Crítica y Apologética del Arte de llevar la Cuenta y Razón contra la opinión del Barón de Bielfeld acerca del Arte General y del Método de Partidas Dobles en Particular. A lo largo del contenido de esta obra hemos podido comprobar la similitud de argumentos entre el proyecto que el Contador General de Indias, D. Francisco Machado (1780) presentaba al rey: Papel de Consideraciones..., y que recogía con el desarrollo de nueve puntos las ventajas del nuevo método y sus posibles detractores. Por otra parte, existe una diferencia en los objetivos que se persiguen con uno y otro trabajo; el del Contador General por estar más orientado a una práctica concreta, representa más un manual de contabilidad pública, mientras que el libro de Jócano profundiza algo más en los fundamentos teóricos y metodológicos del método.

Esto no significa, en modo alguno que Jócano copiase el memorial de Machado; otra cosa es que tuviese muy cerca el trabajo de Machado en el momento de redactar el suyo; y que, con su obra, quisiese rendir un homenaje a su superior, aunque, en ningún lugar de su libro haga mención ni a Machado ni a la experiencia que ambos vivieron de 1784 a 1787 , cuando de manera efectiva se aplicó el método de la partida doble en Indias. En nuestra opinión, Jócano quiso efectuar su propia aportación a la causa perdida por Machado y contra todos aquellos que no entendieron o no quisieron entender los argumentos del Contador General en favor de la aplicación del método de la partida doble en la Real Hacienda de Indias.

(14). Sobre este autor, AECA, en su serie de Estudios de Historia de la Contabilidad, ha publicado una reedición del libro de Sebastián de Jócano acompañado de un estudio realizado por RAFael y Alberto Donoso [1998] sobre su vida y obra, que lleva por título: Presentación y estudio introductorio sobre la vida y obra de D. Sebastián de Jócano y Madaria (1738-1821). 


\section{VUELTA A LA INSTRUCCIÓN DE LANDAZURI DE 3 DE SEPTIEMBRE DE 1767}

Ortiz de Landazuri, Contador General durante el período 1764-1777, volcaría todo su esfuerzo en corregir la situación caótica en la que se encontraban las cuentas de Indias y la Contaduría General, ya que ésta era la responsable ante el Rey, del suministro de informes de tipo económico y cuentas que reflejasen el estado de la Hacienda indiana. Todo esto le llevaría a suponer que elaborando unas instrucciones prácticas, sobre ordenación (15), y cortes y tanteos (16), para las Cajas Reales y Tribunales de Cuentas se atajaría el problema de raíz. Veamos brevemente cuál era el contenido básico de las mismas:

En Madrid, el 18 de julio de 1766, elaboraría la primera instrucción práctica (17), dedicada a la confección de los cortes y tanteos de todas las cajas de América, para saber la situación que gozaba cada una. Su objetivo era instruir al personal y homogeneizar los procedimientos utilizados, así establecía que los contadores a la hora de realizarlos debían proceder de la siguiente forma: constaría de tres partes: un encabezamiento donde se expresara lo debido cobrar, que se le hacía cargo a los oficiales; una columnilla a continuación de lo cobrado, donde se diese detalle de cada partida que entra en el arca y de la persona que la entrega; al final del período de cobro se sumaría esta columna central, y por último un pie donde se sacase èl total cobrado al margen derecho o columna de cargo. Por la diferencia entre la cantidad expresada en el encabezamiento y la de lo cobrado, se determinaban el saldo o alcance de lo no cobrado. Todo esto no se llevaría en los libros de cuentas, sino en una relación jurada, totalmente aparte de la contabilidad.

(15) La ordenación de los cargos y datas, consistía en la elaboración o formación de un libro de pliegos horadados, que contenía un resumen de todos los cargos ( $1 .^{\mathrm{a}}$ mitad) y de las datas (2. ${ }^{a}$ mitad), pero ordenados por ramos o productos de la Real Hacienda.

(16) El corte y tanteo consistía en un cuadro resumen de las existencias y dinero que había en la Caja Real, y lo que de ellas había generado cada Ramo o Producto de la Real Hacienda. Según Fco. Machado: «el tanteo no sólo estaba dirigido a investigar la entrada y salida, de los caudales y efectos de Caja, sino también para comprobar si en ella hay todo lo que debe haber», A.G.I. Sección Indiferente General, legajo 1712.

(17) La instrucción práctica para formar los cortes y tanteos, sería presentada por D. Thomas Ortiz de Landazuri, el 18 de julio de 1766, aprobándose el 23 del mismo mes y ordenando su aplicación a partir del 19 de agosto de 1766. A.G.I. Sección Indiferente General, legajo 989. 
En cuanto al corte y tanteo el formato que se le dio varió con el tiempo tendiendo a perfeccionarse, tal y como presentamos a continuación, ver Anexo (Figura 1, p. 30: Plan de corte y tanteo de 1776).

El 3 de septiembre de 1767, se emitía una nueva instrucción (18), a la que podemos considerar como la primera de su clase, y cuyo objetivo principal era dotar de homogeneidad y uniformidad el acto de presentación y ordenación de las cuentas y libros que se recibían de las Cajas Reales de Indias, a través de sus respectivos Tribunales de Cuentas. De dicha instrucción destacamos los siguientes aspectos:

- Las Cuentas y Libros: la única referencia que hace es cuando indica que deben ser claros.

- La competencia de la ordenación: el Tribunal de Cuentas sólo debía admitir las cuentas que se entregasen ordenadas (ley 51, tít. 1 , lib. $8^{\circ}, 1681$ ), competencia que según Landazuri correspondía inicialmente al Tesorero. No obstante los Tribunales disponían, sin embargo, de contadores ordenadores para los casos en que no se cumpliese con lo establecido, soportando en este caso los gastos la Caja Real correspondiente.

- El contador que ordenaba la cuenta, se consideraba incompetente para la glosa y fenecimiento (19) de la misma.

- En qué momento se realizaba la ordenación de las Cuentas: una vez hecho el corte de Caxa a 31 de diciembre, los Oficiales Reales, podían comenzar la formación y ordenación de las cuentas.

- La ordenación se haría en papel común agujereado, registrándose los cargos por clases según su naturaleza y cada ramo de forma individualizada.

(18) : «nstrucción dịspuesta por la Contaduría General, con el fin de instruir á los Oficiales Reales, Tesoreros, Depositarios y demás personas que perciban caudales de la Real Hacienda en al América, y que deban dar cuenta en el modo y reglas que deben observar para la ordenación de las que han de presentar desde 1 de enero de 1768 en adelante en los Tribunales de México, Lima, y Santa Fé, y otros de aquellos dominios»", A.G.I. Sección Indiferente General 1712.

(19) Glosa: nota o reparo que se pone en las cuentas (J. Casares, 1942).

El fenecimiento consistía en una especie de informe de auditoría donde șe establecía las responsabilidades económicas derivadas de la glosa y una vez que los oficiales responsables habían aportado en su defensa la oportuna documentación; indicando al mismo tiempo, las correcciones oportunas y si se habían detectado errores o fraudes en la labor de los Oficiales Reales. De ser así se procedía a ejecutar contra los responsables, las diferencias detectadas en el proceso, las cuales debían ser subsanadas cuanto antes. 
- La estructura de la ordenación de cuentas incorporaba partidas que antes no se manifestaban, como eran los derechos de cobro y las existencias.

Para realizar la ordenación se extraían de los libros particulares y auxiliares los cargos y las datas. Pero, previa a esta operación de traslado, debían registrarse dos cargos, el primero recogía la situación que heredaban del año anterior, donde se reflejaba el líquido existente en la Caja Real a principios de año, y a qué ramos correspondía y, en el segundo, los derechos de cobro que habían sido admitidos en data el año anterior, ver Anexo (Figura 2, p. 31). Debemos, sin embargo, realizar una aclaración en relación con este segundo cargo, argumentando que, tal y como mostramos en el Anexo (Figura 3, p. 32), los Oficiales Reales debían responder y asumir como alcances contra ellos, sólo el valor de los fondos que debía haber, a la hora del cierre de la contabilidad, en la Caja Real (cobrado menos pagado). "Lo debido cobrar y no cobrado» lo registraban no en los libros de cuentas sino en una relación jurada (20), cuyo total se admitía en data, al final de «la ordenación», de esa forma obtenían el líquido de Caja. Al año siguiente, esa cantidad que había sido admitida en data, se volvía a cargar en «la ordenación» mediante un segundo cargo. Debemos decir que este segundo cargo de los derechos de cobro, no suponía registro en los libros de cuentas que se llevaban normalmente, ya que en ellos sólo se registraban las entradas y salidas de numerario. A continuación se daba traslado a las salidas por pagos realizados o datas, utilizando un pliego para cada tipo de gasto o pago realizado.

(20) Hasta la creación de los Tribunales de Cuentas, no era normal que los Oficiales Reales entregaran una relación jurada de cuentas, ya que ellos sólo se hacían cargo de los fondos líquidos que había en la Caja Real. Tras la creación de los Tribunales, los Ofíciales Reales plantearon un conflicto, como fue el caso de Méjico, ya que las ordenanzas por las que se regían, exigían que los Oficiales Reales respondiesen no sólo de lo ingresado en la Caja, sino también de "lo debido cobrar». Sánchez Bella [1991, p. 666] relata, que se abrió un amplio expediente donde se trataba de averiguar si los Oficiales Reales debían dar relaciones juradas de lo debido cobrar, para hacerles cargo de ese dinero. Los Consejeros de Indias quisieron asegurarse, dando origen a una Real Cédula, dirigida al Tribunal de Cuentas de Méjico pero que hizo extensiva a los restantes, donde se ordenaba a los Oficiales Reales que dieran cuenta "no solamente de lo cobrado, sino de lo debido cobrar", "con relación jurada so pena del tres tanto, conforme a las leyes reales, uso y costumbre de la Contaduría Mayor de estos Reinos de Castilla, eximiendoles de esa pena a lo debido de atrás» (R.C. 20 de mayo de 1629 dirigida al Tribunal de Cuentas de Méjico. A.G.I. Sección de Méjico, legajo 320). Documentación recogida en la obra de Sánchez Bella [1991, pp. 666-669]. 
Como conclusión de la ordenación de cargos y datas se representaba la situación final, mediante un cuadro resumen, donde se recogían por cada uno de los ramos lo «debido cobrar», lo «cobrado» y lo «debido cobrar y no cobrado"; así como el global de datas. Este estado final se correspondería con la situación inicial del año siguiente.

Esta instrucción ( 3 de septiembre de 1767) a la que se volvería el 25 de octubre de 1787, no recogía, en ninguno de sus puntos, "reglas» para llevar las cuentas diarias en los libros, quedando al arbitrio de los Oficiales Reales y sus subalternos la forma y contenido de los registros contables. Tampoco establecía un modelo práctico y claro que sirviese de ejemplo para aplicar dicha instrucción, dando lugar a su total incomprensión e ignorándose su aplicación, tal como nos lo muestra un documento que hemos localizado (21) en el que se recogen todas las incidencias - conocidas a través de la Vía Reservada- acaecidas durante el mandato de Landazuri como Contador General.

Todo ello hacía que la revisión de las cuentas por el Tribunal fuera un proceso lento dando lugar a un retraso considerable, con lo cual muchas de las reclamaciones ordenadas por el Tribunal de Cuentas quedaban sin efecto ya que cambiaban de destino, fallecían o sus fiadores no estaban en buenas condiciones económicas como para afrontar las resultas impuestas, en cuyo caso se le embargaban los bienes, poniéndose en arrendamiento, hasta cubrir la deuda con el fisco, con lo cual quedaba embargado no sólo el titular o fiador, sino también sus posibles herederos

\section{EL DEFENSOR DEL NUEVO MÉTODO EN LIMA: EL CABALLERO DE CROIX}

El proceso seguido en el Virreinato de Perú, lo encontramos perfectamente sintetizado en una representación que el Virrey De Croix envió a Antonio Valdés y que reproducimos íntegramente por su interés histórico contable:

«El caballero de Croix, siendo Virrey del Perú recibió una R. Orden de 25 de octubre de 1787, en que se mandaba cesar un método de Cuenta y razón que por otra de 20 de abril de 1785 se habia man-

(21) «Indice general y exacto de los informes, consultas y representaciones que sobre diferentes negocios, y materias de Gobierno, Real Hacienda y otros hizo a S.M. por la vía reservada de Indias el Sr. D. Thomas Ortiz de Landazuri desde el ingreso al empleo de Contador General hasta agosto de 1777, en que falleció", A.G.I. Sección Indiferente General, legajo 995. 
dado observar, y observaba en aquellas Caxas Reales arreglados a una Instrucción formada por la Contaduria de Indias, y aprobada por el Rey en el año de 1784.

El Virrey se instruió suficientemente de la materia antes de hacer novedad y advirtió, que en la expedición de dicha R.Orden precisamente se habia procedido con equivocación, y sin haberse podido tener noticia del estado que tenia en el Perú el establecimiento del metodo de Cuenta y razón de la Instrucción de 1784, llamado Partida Doble. Siendo evidente todo esto asi como los beneficios que V.M. estaba ya disfrutando, y los perjuicios irreparables que se le iban a ocasionar; debia el Virrey suspender la execucion de la Real Orden como lo disponen las Leyes de Indias.

No los hizo sin embargo por solo su dictamen, sino que dio aquellas disposiciones, y providencias que se acostumbran para instruir, y resolver los negocios mas graves del Gobierno: y por estos tramites numerosa y solemne que las Ordinarias: y ella fue parecer que se suspendiese la execución de la Real Orden interin se formaba una instrucción que asegurase, e hiciese posible su cumplimiento, y se diese cuenta de todo a V.M. Asi lo hizo el Virrey conformandose con el Acuerdo de la Junta.

Sabe ahora, que se han desaprobado todas sus disposiciones, y providencias, mandando que se cumpla la Real Orden, pero sin resolver sobre el Acuerdo de la Junta, que era lo que se consultaba a V.M.

La desaprobación en estos terminos solamente recae sobre el Virrey, cuias disposiciones y providencias no pudieron ser mas ajustadas al Orden regular de substancias los Expedientes: El Virrey no es insensible á una Real desaprobación ni lo puede ser a los perjuicios que sentirá el servicio de V.M. ni a los beneficios de que se le priva.

Por ambas consideraciones, solicita y suplica que el expediente se examine nuevamente por inteligentes en negocios de Cuenta y razón de la Real Hacienda de Indias: lo primero para poner remedio en lo que toca al servicio de V. M.; y lo segundo para que se aprueben quantas disposiciones y providencias dio en el asunto, como corresponde al merito de ellas, y a salvar el honor y reputación del Virrey y de su Gobierno. 31 de diciembre de 1790" (22).

Tal y como nos'muestrá el documento, con el que hemos abierto este expediente, De Croix, Virrey del Perú, abanderó y promovió todo el proceso de reclamación, para mantener la áplicación de la Partida Doble en su territorio, hecho que nos ha llamado poderosamente la atención, no en balde el profesor Ramos Ceŕveró [1992, p. 27] lo considera como el «primer paladín» en la defensa de la parțida doble. Por esa razón cree- 
mos que merece la pena destacar algunos aspectos de su biografía [Mendiburu, 1932, pp. 239-287] y gestión al frente del virreinato.

\subsection{El Virrey, Caballero De Croix}

Natural de Lila en el antiguo Flandes, De Croix gozaba de los siguientes títulos: Comendador de la distinguida Orden Teutónica (23), Teniente General de los Reales Ejércitos, primer Teniente de la Compañía Flamenca de Reales Guardias de Corps.

Fue nombrado virrey del Perú en 1784, sustituyendo, en el cargo, a D. Agustín de Jáuregui. Llegaba al Callao el 4 de abril de ese mismo año y a Lima dos días más tarde. Su recepción pública se llevaba a cabo el 25 de agosto de 1784 .

Corresponde a la administración de Croix la creación de las intendencias de provincias - Trujillo, Tarma, Lima, Guancavélica, Guamanga, Cuzco y Arequipa-, en cumplimiento de la orden real de 5 de agosto de 1783 y de las ordenanzas de 28 de enero de 1782 . El visitador general D. Jorge Escobedo y Alarcón que sucedió a D. José Antonio Areche, en 1784, propuso las personas que debían servir de intendentes, y se nombraron con títulos que aprobaba el rey en 24 de enero de 1785 (24).

El 13 de julio de 1784 creaba en Lima la Junta Superior de Real Hacienda, cuya función era conseguir en todas las provincias un método uniforme para el gobierno y administración de la Real Hacienda (25).

(23) La Orden Teutónica era una institución militar y religiosa creada en San Juan de Acre en el año 1190 para atender en hospitales a los cruzados enfermos, orden que después pasó a Europa y llegó a poseer grandes riquezas.

(24) 'Las intendencias se adjudicaban de la siguiente forma: la de Trujillo, a D. Fernando de Saavedra que era contador de la visita general; y fue su teniente asesor D. Juan Bazo y Berri que había sido empleado en el estanco de tabacos. La de Tarma, al coronel D. Juan María Gálvez de la orden de Carlos III, con el teniente asesor Dr. D. Bartolomé Bedoya. La de Guancavélica, al oidor de Lima D. Fernando Márquez de la Plata, y teniente asesor Dr. D. Pedro José Méndez. La de Guamanga, al contador mayor del Tribunal de Cuentas D. Nicolás Manrique de Lara, marqués de Lara y de teniente asesor Dr. D. José Muñoz. La de Cuzco, a D. Benito de la Mata Linares, oidor de Lima, con el teniente asesor D. José de Zaldívar. La de Arequipa, al director general de Aduanas D. José Menéndez Escalada y teniente asesor D. José de Escobar. La de Lima quedó a cargo del visitador general D, Jorge Escobedo y su teniente asesor D. Manuel María del Valle, pasaba después a manos del virrey, hasta 1805. Estas siete intendencias se dividieron en partidos o subdelegaciones que formaron el número total de cincuenta y cuatro.

(25) Esta Junta se reunía en sesiones semanales, y estaba formada por un presidente, un regente, un oidor, el fiscal de lo civil, un contador mayor y uno de los oficiales reales además de dos relatores y un escribano. 
Infatigable defensor de la claridad y buena administración, cumplía con exactitud (26) la Real Orden de 27 de abril de 1784, que mandaba establecer la contabilidad por partida doble en las oficinas de la Real Hacienda cuando, por otra Real Orden de 25 de octubre de 1787, se imponía la restauración del antiguo método de partida simple. Para responder a este hecho De Croix, con gran esfuerzo, conseguía reunir un expediente que contenía las exposiciones y opiniones de los Oficiales Reales, Jefes de Aduana y Tribunales de Cuentas, sobre el particular y al que dedicaremos algunas páginas más adelante.

Hombre celoso y observador en materia de cuentas, recopiló informacion sobre todas aquellas personas que estaban directamente implicadas en el proceso que seguían las mismas; persiguiendo como objetivos el proporcionar una mayor racionalidad a la administración de la Real Hacienda así como una mayor economía y dinamismo. En su afán, se atrevió a presentar al Secretario D. Antonio Valdés, el 16 de junio de 1788, un informe (27) donde no sólo exponía las posibles causas de la lentitud en las cuentas de la Real Hacienda sino que también planteaba unas propuestas de jubilación de determinados señores y el nombramiento de otros con capacidad suficiente no sólo para desempeñar su cargo sino también para enseñar a los demás. Informe que nos va a proporcionar un primer contacto con personajes que posteriormente trataremos y que por su interés exponemos a continuación:

«El Virrey del Perú.

Estoy persuadido a no dudar por lo que tengo observado desde mi llegada a este Reyno, y por lo que con la más cuidadosa meditación voi viendo desde que se me agregó la Superintendencia, que el origen y principal causa del desorden y atrasos notados en el manejo de la Administración de los Ramos y Rentas de este Erario, y en su cuenta y razón, proviene en la mayor parte, o en todo, del poco cuidado que se ha tenido en la elección de lo's sugetos en quienes comunmente se han proveido las primeras plazas de Ministros y Gefes de los Tribunales y Oficinas de Real Hacienda.

Este punto según mi opinión, es de la mayor importancia de las Americas, y en esta más que ninguna otra parte por su distancia de la Metrópolis y por otras muchas razones, y por tanto juzgo, que para conseguir se haga al servicio del Rey como corresponde, es necesario procurar tomar algún temperamento para que se remedie por lo menos en lo que más urge; y que eń adelante se ponga el mas es-

(26) Se habían elaborado instrucciones prácticas y modelos por personal entendido en la materia (Di Juan de Oyarzabal).

(27) A.G.I. Sección Lima, legajo 677. 
crupuloso y detenido cuidado en las elecciones de los sugetos que se nombren para ocupar las vacantes de los primeros empleados de las oficinas, pues juzgo que solo de este modo se podrán precaver el desorden y los atrasos que aun subsisten en algunos de ellos, y que se vaya poniendo con el tiempo este Erario en el buen orden de administración y economía por tanto necesita y recomienda la incomparable bondad de nuestro augusto soberano con Ministros y Gefes de probada inteligencia, rectitud, desinterés y buen zelo, no solo resulta la gran ventaja de que se haga bien el servicio del Rey y del público sino también el que los subalternos de las oficinas logren bajo su enseñanza y dirección las necesarias instrucciones que los hagan útiles con el tiempo para el manejo de los asuntos de la Real Hacienda. (...)

En la Contaduría de la Real Aduana se notaba bastante atraso y falta de orden en su despacho y operación a causa de la poca disposición y abanzada edad de su contador D. Juan de Echevarria. Con motivo de la oportunidad que su vacante ha proporcionado he logrado poner en ella a D. Francisco Uralde como tengo dada cuenta a V.E. en 5 del corriente. Con este sugeto y su actual administrador D. Joaquín de Arreze me persuado que el despacho y operaciones de esta atendible aduana se pondrán en el buen orden y simplificación que necesitan las delicadas partes del manejo de sus Ramos tanto para que el público sea bien servido, como también para que se consigan aumentos y ventajas que se deven esperar de una justa y cuidadosa administración en esta importante oficina.

En la Real Caxa de esta ciudad se hallan ambos Ministros, Contadores y Tesorero en abanzada edad, y en estado de no poder hacer el servicio con la aptitud que forzosamente piden los delicados asuntos que en ella se manejan...

... en las Caxas Matrices de esta Capital y en el Tribunal de Cuentas, es donde se deben instruir y formar los sugetos útiles para destinarlos a las plazas primeros que vacaren en las oficinas foraneas, pues solo de este modo juzgo se podrá conseguir el arreglo de ellas y buen servicio...

Los tres contadores que hoy tiene la Mesa Mayor haciendo referencia al Tribunal de Cuentas), son el Marqués de San Felipe el Real, el Marqués de Lara y D. Pedro Dionisio Gálvez, ... Me parece según tengo observado y por las noticias con que me hallo, que uno y otro nada otra cosa hacen más que firmar los informes y autorizar las operaciones que los subalternos del Tribunal las forman. Por esta razón se hallan bastantes cuientas y asuntos atrasados, sin embargo de las muchas manos que hai en el, ...

Por eso juzgo que S. Felipe se le deve jubilar con preeminencia y sueldo entero, ... 
Su vacante convendrá se confiera a $\mathrm{D}$. Juan de Oyarzabal Ministro Comisionado por Real Cédula de 22 de febrero de 1787, para el establecimiento en este Reyno de la Cuenta y Razón por partida doble. Este sugeto, sobre su acreditada inteligencia y práctico conocimientos en el manejo de los Ramos y Oficinas del Reyno, es laboriosa y de probada buena conducta en las varias comisiones y encargos que se han puesto a su cuidado.

Tengo entendido que el Marques de Lara, con la mira de llevar y establecer su familia en España, ha solicitado dejar la plaza tanto por este motivo como también porque según estoi informado parece que conoce no puede combinar su modo de pensar con las obligaciones que pide el destino que ocupa... Juzgo que las tres plazas de la Mesa Mayor de este Tribunal se podrán reducir a dos."

El 25 de marzo de 1790 entregaba, el teniente general Caballero De Croix, el mando del virreinato a su sucesor el general de Marina D. Frey Francisco Gil. Retirándose al convento de San Pedro, donde estuvo hasta el 17 de abril, embarcando, en esa fecha, hacia España. El rey le nombró coronel de Guardias Walonas y le condecoraba con la Gran Cruz de la Orden de Carlos III. La imagen que se tenía de él en Lima era la de un hombre que destacaba por su religiosidad, buena conducta y acciones bondadosas y caritativas. Fallecía en Madrid el 8 de abril de 1791.

\subsection{Teodoro De Croix, defensor de la Partida Doble}

De Croix daba mucha importancia a la Real Hacienda, llegando a considerarla como uno de los pilares básicos para el gobierno de aquel territorio. Opinaba que el dominio de tal materia era una cualidad que se reconocía a los "grandes Príncipes y de los más excelentes Virreyes del Perú y en especial D. Francisco.de. Toledo (de quien se puede decir y dicen que estableció el régimen y gobierno político y económico de aquellos riquísimos y dilatados Reyno)» (28). Fue éste quien le enseñó que los asuntos de Real Hacienda constituían unas de las principales obligaciones del virrey. Su antecesor en él cargo, el Marqués de Montesclaros, decía:

«... que el virrey ha de ser en el Perú Oficial Real, Proveedor y Pagador, $y$ aun intervenir a otros ministerios».

(28) Informe dirigido al Rey el 30 de diciembre de 1790. A.G.I. Sección Indiferente General, legajo 1712 . 
Cuando se le encomendó a De Croix la Superintendencia de su Real Hacienda, en aquel reino, ya se había establecido el nuevo método de cuenta y razón. Describiendo en sus memorias, la gran fascinación que le había causado el nuevo método, con las siguientes palabras:

«Desde luego tube la satisfacción de ver que en esta Real Caja y Real Aduana, que son las oficinas de mayor extensión y complicación en sus cuentas, se estableció el nuevo método con grandísima felicidad, y que lo mismo iba suicediendo en las Cajas francas, Administraciones de alcabalas y en otras varias oficinas, distinguiendose á clara luz la facilidad con que en todas se lograría el establecimiento con poco trabajo, y la gran utilidad que resultaría á la Real Hacienda, al público y á los mismo Ministros por la seguridad del manejo" (29).

Sin embargo, la actuación del Virrey De Croix no se quedó sólo en simples elogios al nuevo método, sino que al ver la importancia de la materia, obligó su aprendizaje a todos los Oficiales Reales, estableciendo como requisito indispensable para promocionarse o pedir destino el conocimiento del nuevo método, hecho que debían certificar los propios contadores comisionados para su establecimiento, tal y como indicaba en uno de sus informes remitidos a D. Antonio Valdés (30):

«..., crei que uno de los mayores servicios que podía hacer al Estado era celar que en todas las oficinas se adoptase y executase esta Instrucción — Real Orden de 20 de abril de 1785- a cuyo fin havia dado varias y eficaces providencias en el designio de instruir a todos los empleados de la Real Hacienda en este método mandando que ninguno pudiese solicitar ascenso ni otro destino sin acreditar primero estar instruido en el nuevo método de cuenta y razón, trayendo certificación de los Ministros Comisionados para su establecimiento.

Con esta providencia conseguí que muchos empleados se instruyesen perfectamente del nuevo método con grande facilidad y en muy pocos meses.»

Sin embargo, al recibir la Real Orden -de 25 de octubre de 1787-, a finales de abril de 1788, por la que se derogaba el método establecido, quedó sorprendido y muy disgustado ya que, en esos momentos, se estaban superando las dificultades de la implantación del nuevo método y se empezaban a ver los resultados. En una carta enviada por el Caballero

(29) Memoria de los virreyes que han gobernado el Perú, durante el tiempo del coloniaje español, tomo V, D. Teodoro De Croix, pp. 305 a 312. Lima, 1859.

(30) A.G.I. Sección Lima, legajo 688. 
De Croix, por Vía Reservada, a D. Antonio Valdés, le pone de manifiesto la situación con las siguientes palabras (31):

«... quando me hallaba lleno de complacencia, por ver la felicidad con que en esta Real Caxa, y Real Aduana, y también en las mas de las Caxas, y Administraciones foráneas se había llevado el año anterior de 1787, primero del establecimiento, el nuevo método, comprobandose sin temor de duda, con los Estados mensuales, y anuales, y algunas cuentas remitidas al Tribunal, despues de haberse vencido la árdua empresa, principalmente en éstas Caxas, de la Liquidación de los Ramos Particulares, y agenos, y de los créditos activos, y pasivos de este Erario, que siempre estuvieron en el caos mas confuso, de modo que contaba con que en breve término lograría en todas partes su perfecto establecimiento con solo hacer las anotaciones, y reparos oportunos á los que hubiesen dirigido defectuosos los libros, y despachando algún oficial inteligente á la caxa donde por absoluta impericia, ó por malicia, hubiese necesidad.»

El Virrey, que ya tenía conocimientos de partida doble (32), consideró las ventajas de este método, frente al de cargo y data. Al ver que su establecimiento significaba una reforma positiva para la Real Hacienda, decidió intervenir en defensa del Método de la Partida Doble. Para ello utilizaría todos los medios que la ley ponía a su alcance, como era hacer uso de la facultad de poder dejar en suspensión temporal, aunque se hubiese decretado el «cúmplase», informando al monarca «una, dos y hasta tres veces, como hicieran siempre los virreyes». Medida que, sin embargo, podía tomiar, haciendo uso de una de las facultades que el virrey gozaba, como era la posibilidad de convocar Juntas Extraordinarias de Hacienda, siempre que se estimase que el alcance de una Real Orden iba en contra de los intereses reales [Ramos Cerveró, 1992, p. 23].

Para poder informar, de manera adecuada al rey, puso el asunto en conocimiento de los Fiscales, quienes aconsejaron que al tratarse de un tema tan delicado se pidiesen informes a personas entendidas en la materia, como los ministros de la Real Aduana, contadores del Tribunal de cuentas y Oficiales Reales (33).

(31) A.G.I. Sección Indiferente General, legajo 1712.

(32) Según Ramos Cerveró (1992, p. 23) De Croix, tardó dos años en comprender el método de partida doble, «circunstancia que ensalza su figura por cuanto no parece propio de la función de un virrey dedicarse a la investigación contable o al menos de la de los principios que inspiran su técnica».

(33) «Los fiscales en vista de la Real Orden de 25 de octubre del año pasado de 87, dicen: que V.E. tiene mandado que se guarde y cumpla y para proceder a su devida execucion se ha servido dar vista a los fiscales para que pidan aquello, y para poderlo hacer con más conocimiento, podra V.E. mandar que informen los Oficiales Reales y el Real Tribu- 
Así, con fecha 20 de febrero de 1789, dirigía una carta (por la Vía Reservada) a D. Antonio Valdés, Secretario de Indias, donde le comentaba, que antes de llevar a cabo lo establecido en la instrucción, de 25 de octubre de 1787, había estudiado el cambio y pedido informes a personas expertas en la materia sobre la conveniencia, o no, de realizar dicho cambio a mitad de año, los cuales habían respondido unánimemente:

"Que sería mui arriesgada la operación de cortar las cuentas de dicho año ya empezadas por el nuevo método y seguir despues en los mismos libros, o por separado, la de los meses restantes por el anterior de cargo y data, pues era consiguiente el trastorno, y confusión que imposibilitaría la ordenación, y liquidación, si las cuentas no comprendían el año completo en el mismo método.»

Con esta manera de proceder, el Virrey, mostraba la preocupación y sensibilidad ante los asuntos de tipo económico, interesándose y pidiendo informes que le instruyeran, a personas con conocimientos en la materia; asimismo demostraba su admiración por el nuevo método, principalmente por la claridad y prontitud con que se cerraban y presentaban los libros de cuentas en los Tribunales. De este modo, haciendo alusión al método de la partida doble, y en particular a la Instrucción de 27 de abril de 1784, decía (34):

"Y siendo la Real Hacienda un Ramo tan principal, y se puede afirmar que principalisimo del Gobierno de aquellos Dominios, no pudo menos de venir a entrar luego en su cuenta y razón: escollo en que tropezaron quantas Reales providencias y disposiciones se habian dado para cerciorarse de las Rentas y cargas de la Real Hacienda, y ordenar con este cierto conocimiento las providencias relativas a su acertado gobierno. A la sazón habia pedido V.M. estas noticia, y debia saber el Virrey el estado de esta Real disposición y de resultas supo que nunca se había podido formar un Estado Justo del Real Erario por la confusión y defectos de sus cuentas. Se dedicó á examinar éste punto: tomó noticia de él y se convenció, a costa de no pequeñas tareas propias, de que en efecto la qüenta y razón hasta entonces no habia podido satisfacer los deseos de V.M., y que solo en el nuevo método podría verificarse, como en efecto se verificó, según expuso remitiendo un Estado completo de la Real Hacienda (35), con partes esenciales hasta entonces no comprehendidas y mucho menos liquidadas."

nal de Cuentas y con el que hagan una vista. Lima 24 de abril de $1788 »$, A.G.I. Sección Lima, legajo 688 .

(34) A.G.I. Sección Indiferente General, legajo 1712.

(35) Este estado completo, está localizado en el A.G.I. Sección de Lima, legajo 688. 
Para Ramos Cerveró [1992, p. 27], De Croix «se adentró en el conocimiento de la partida doble más allá de donde era usual, incluso entre los tratadistas especializados y en los hombres de negocios de la empresa privada, comprendiendo su filosofía y sus ventajas».

Los informes pertinentes fueron solicitados a los siguientes expertos (36):

- En la Real Aduana:

- D. Francisco de Uralde (contador) (37).

- D. Joaquín José de Arreze (administrador).

- En la Caja Real:

- D. Diego Sáenz de Ayala (tesorero).

- En el Tribunal de Cuentas:

- D. Pedro Dionisio de Gálvez (contador).

- Otros:

- D. Juan de Oyarzabal (38) (contador interventor para el establecimiento del nuevo método).

Pero veamos los argumentos más significativos de cada uno de ellos en favor del método de partida doble:

Francisco Uralde reconocía que:

- Al igual que el método de cargo y data, este nuevo método también estaba expuesto a errores, como era natural. Pero con la diferencia

(36) Todos estos informes componen un expediente, formado por cuatro cuadernos, denominado: «Expediente formado a consecuencia de la Real Orden de 25 de octubre del año pasado de 1787, relativa a la extincion del Nuevo Método de Partida Doble», núm. 371. Y que hemos localizado de forma completa en el A.G.I. Sección de Lima, legajo 688. Este mismo documento se puede hallar, pero incompleto, en la Sección Indiferente General, legajo 1712 .

(37) Contador de la Real Aduana de Lima y había servido anteriomente en la Caxa de Trujillo hasta final de 1787, habiendo entregado en el Tribunal de Cuentas las correspodientes al año 1787, llevadas por el método de Partida Doble. Así como seis meses de 1788. A.G.I. Sección de Lima, legajo 688.

(38) Oyarzabal y Olavide, D. Juan: Era Contador de Resultas del Tribunal de Cuentas en 1782. El Virrey De Croix comisionó a Oyarzabal para establecer en el Perú la cuenta por partida doble en las oficinas. Lo verificó en algunas venciendo los embarazos opuestos por antiguos empleados. En 1788 pasó a Chile, fundó allí el Tribunal de Cuentas e implantó diferentes reformas para el buen orden de la hacienda. En el año 1811 regresó a Lima para servir la superintendencia de la Casa de la Moneda, cargo que desempeñó hasta 1818. Fue consejero honorario del Supremo Consejo de Hacienda. M. MENDIBURU: «Diccionario Histórico Biográfico del Perú», Lima 1934, vol. VIII, p. 314. 
de que en éste eran fácilmente detectables, mientras que con el de cargo y data no, a pesar del tiempo que este último llevaba implantado.

- El nuevo método comprendía las deudas activas y pasivas de la Real Hacienda, así como las cuentas de las especies y efectos, que no se incluían en el de cargo y data; afirmando que:

«ni se había visto en la America hasta aora siendo partes tan esenciales para la seguridad de una Administración, pues dejaban principalmente en las deudas activas, la libertad de ocultar las cobradas y mal versan los caudales, cuyo riesgo evita el nuevo metodo haciendo demostración mensualmente del estado de ellas; circunstancia atendible y útil para el servicio».

- También reconocía su facilidad a la hora de emitir informes sobre determinadas partidas:

«La facilidad que presta el nuevo método también es apreciable para evacuar informes y consultas, por la claridad de la cuenta de Rezagos donde se puntualizan las deudas antiguas, la de Diversos Deudores...»

- Además, establecía la ventaja de la separación de los distintos ramos, pudiéndose dar una puntual información de cada uno de ellos:

«... los Ministros pueden puntualizar los ramos particulares, y agenos, por que se ha liquidado el haver lexitimo de cada uno y se lleva en el nuevo metodo con tal separación distinguiendose el estado de ellos para el gobierno de sus aplicaciones, remisiones o pagos lo que no podía practicarse por el anterior metodo, así por que faltaban las citadas cuentas del libro de Caxa como por que los ramos particulares estaban confundidos con los de Real Hacienda..."

- En referencia a la carga de trabajo de los Oficiales Reales, reconocía que se lograba una reducción en las tareas; ya que antes las partidas del Manual en las Cajas Reales se pasaban directa e íntegramente al mayor y posteriormente a la Ordenación de los Cargos y Datas - que ellos denominaban ordenatas-; ahora, con el nuevo método sólo se hacía una breve indicación en los libros mayor y de caxa. Además, veía una ventaja importante en la reducción del volumen de los libros, así decía:

"La diferencia material del volumen de los libros, es el mejor comprobante del adelantamiento en el ahorro de las Caxas Reales. El Manual de las de Truxillo del año 87 por el nuevo metodo tiene 
62 foxas de papel común y el anterior tendrá como 200. Igual volumen tenia el mayor de las Ordenatas que duplicandose estas y los libros consuman mucho papel y tiempo para escribirse, y según la regulación que he hecho hasta aora con un pliego para lo que antes se gastaba sinco.»

- De lo anterior se deducía una evidente reducción de tiempo en la formación de duplicados y en la presentación de los libros ante el Tribunal de Cuentas, reduciéndose el tiempo de glosa y fenecimiento de las mismas. Este hecho evitaba un perjuicio para la Real Hacienda y así lo declaraba:

«..., por que muchos de los Alcances se han por no haver contra quien repetir a causa del transcurso del tiempo, y otros han bastado a los ministros por que aquellos contribuyentes contra quienes deben repetir murieron se ausentaron o se atrasaron, cuyo punto es de la mayor atención, y que necesita recomendarse particularmente, pues de sufrir las anteriores demoras, se seguirían indispensablemente estos sacrificios de la Real Hacienda...»

José Joaquín de Arrese: su breve informe lo basaba en su experiencia personal como administrador de la Real Aduana de Lima y haciendo hincapié en la falta de control existente, con el método de cargo y data, sobre los derechos de cobro relativos al comercio y tráfico de barcos, así como la difícil recaudación de las cuotas señaladas a los gremios que componen un "catálogo de individuos Deudores y de unas sumas tan cuantiosas que para su manejo y exacción no son bastantes todas las atenciones y desvelos de la más activa y celosa Administración. Estas importantes tareas se hacen más espendibles con el nuevo método».

Diego Sáenz de Ayala: el informe (39) de este Oficial, de la Caxa Real de Lima, nos llamó la atención ya que revelaba, en una especie de memoria, la preocupación inicial que mantenía alterados e inquietos a los Oficiales Reales por la implantación del nuevo método que, por su interés histórico contable, pasamos a transcribir íntegramente, ya que consideramos que recoge el sentir generalizado entre los Oficiales Reales:

«se nos representaba la observación de un metodo que ignorabamos. Dificultavamos su inteligencia por no hallarnos en aquella edad en que se hace facil aprehender quanto se quiera. Aun quando nos quisieramos exforzar a tomar instrućción de este metodo encontrabamos de estorvo e impedimento la variada y numerosas ocupaciones del Ministerio que no nos darian lugar a incubar en los

(39) A.G.I. Sección de Lima, legajo 688. 
principios y reglas de semejante quenta. El arraigado abito del antiguo metodo de llevar la cuenta por tesoreria nos hacia resistencia a la novedad. Y siendo nosotros responsables a los descubiertos de la Caxa exclamabamos llenos de temor como nos podríamos sustentar a un método que no entendiamos? Como no seriamos expuestos a equivocaciones, y errores, que nos causasen el desembolso de nuestras facultades para los enteros? Como no seria esto casi necesario por el nuevo método quando por el antiguo eran tan frequentes los yerros que han ocasionado tanto daño a nuestros Privativos Intereses? Y sobre todo miravamos con horror que huviese devenir a darnos la Ley un Contador Interventor de la Partida Doble sin responsabilidad alguna que dando nosotros a las resultas de las operaciones de este que podrian contener algunos vicios que no pudiesemos descubrir por falta de inteligencia.»

En una segunda parte nos da a entender cómo a medida que iba transcurriendo el tiempo se iban convenciendo de la bondad y exactitud del método de la partida doble y cómo éste era beneficioso para ellos:

«Fortalecieronse estos nuestro temores en los primeros meses del año pasado de 1787 en que sin haver venido la Real Orden para la introduccion del nuevo metodo se dio voluntariamente principio a el para por el Ministro Asociado y Comisionado que de ante mano tuvo por conveniente poner en esta Caxa el Sr. Jorge Escobedo como Superintendente de Real Hacienda. Parece increible, en cada tanteo mensual resultaba un descubierto en esta Caxa y en los quatro meses que duró la comisión de este asociado hasta su retiro al Tribunal Mayor de Cuentas por Real Orden que huvo para ello ascendio el descubierto de la Caxa a mas de 3.000 pesos que tuvimos que enterar de nuestro peculio, despues de sufrir los recelos que de nuestra conducta pudiese quedar en opinión.»

"Pero con la misma sencillez verdad y pureza con que hemos expuesto nuestros antecedentes temores devemos confesar que venido de Real Orden para el establecimiento del nuevo método por partida doble y dado principio a el desde $1^{\circ}$ dia del presente año por el Contador Interventor D. Juan de Oyarzabal se ha disipado todo nuestro horror y confucion por que el infatigable travajo, y a lo de este Ministro nos ha hecho ver practicamente que el nuevo método de la partida doble es facil comprehensivo, que es productivo de una puntual y cabal idea a los Reales Intereses, igualmente que a los del público, ...»

Además, resaltaba seis puntos, a lo largo de los cuales mostraba las ventajas de la partida doble frente al método de cargo y data; la mayoría de ellos recogían aspectos, ya comentados anteriormente, excepto en uno 
de ellos donde reflejaba la preocupación que los Oficiales Reales tenían por los errores que cometían al llevar las cuentas, ya que los alcances derivados de tales equivocaciones los tenían que pagar de su bolsillo y dejando bajo sospecha la actuación del Oficial. Manifestando que esta preocupación desaparecía con el nuevo método:

«Diez meses van vencidos del uso y practica de este nuevo método en esta Caxa Matriz, tan basta en los animos que la gravan con la sola entrada y salida de caudales que han havido meses en que se han sentado 900 partidas de cargos y abonos. En cada uno de ellos se ha hecho el mensual tanteo en mui breve espacio de el de una hora. Y en todos se ha visto la exactitud y fidelidad de la Cuenta no haviendo havido descuvierto de un solo octavo...»

Pedro Dionisio Gálvez: como Contador del Tribunal de Cuentas, basaba su informe en aspectos relacionados con las operaciones que éstos realizaban en materias de cuentas. A lo largo de su informe nos relata y comenta algunos aspectos relacionados con las ordenaciones y tanteos de cuentas. Se quejaba de que, con el método de cargo y data, la ausencia de reglas favorecía la arbitrariedad de los Oficiales Reales y, por tanto, se detectaban diferencias en las cuentas de una misma caja al cotejar las cuentas de un año con otro, o entre las cuentas de un mismo año de distintas cajas.

Advertía, asimismo, de los frecuentes errores que las cuentas tenían, el retraso de presentación de las mismas, y que en muchos casos el Tribunal debía repetir la ordenación, a costa de la Real Hacienda, ocasionando una multiplicación de las tareas propias y un consumo de tiempo innecesario.

Al igual que el Contador General, Francisco Machádo, manifestaba que la ausencia de reglas claras para llevar la cuenta diaria era la causa de que las ordenaciones de cuentas y los tanteos, que se elaboraban una vez concluido el año y terminadas las cuentas, no tuviesen la claridad y exactitud que éstos débían tener. Resaltảndo, que estas ordenaciones y tanteos, no reflejaban el estado de la Real Hacienda, ya que al no incluir en los libros de cuentas los derechos de cobros y existencias, llevados mediante relaciones juradas, en muchos casos se olvidaban de incorporarlas,

Juan de Oyarzabal: que desde muy joven había trabajado en una casa de comercio, para pasar después a trabajar, durante más de diecisiete años, a la Caja Matriz y al Tribunal de Cuentas. Había sido comisionado para la implantación de la partida doble en las Indias, por sus profundos conocimientos en materia de cuentas. 
Oyarzabal, en su extenso informe, da muestra de su gran experiencia en las cuentas de la Real Hacienda en general, y de las cuentas del Virreinato del Perú en particular, ya que al haber trabajado en el Tribunal de Cuentas, fundamenta sus argumentos con numerosos ejemplos aclaratorios. Su exposición la basaba en tres puntos fundamentales:

«1. ${ }^{\circ}$ el modo de llevar diariamente las cuentas de Real Hacienda; $2 .^{\circ}$ formar estados mensuales y tanteos anuales; $3 .^{\circ}$ dar la cuenta general en fin de cada año como esta mandado en las leyes.»

En el primer punto hacía alusión a la diversidad de libros que debían llevar los Oficiales de las Cajas Reales. Asimismo manifestaba que:

«En uno y otro esta de manifiesto no con poca confusión e ignorancia nuestra, que en substancia solo se formaba asiento a las partidas de ingreso o entradas y salidas de los caudales y se omitia en todas el de los adeudos de los valores que quedavan pendientes en el año de los rezagos de los anteriores y lo mismo el de los efectos de Azogue y Papel Sellado, Bulas, Pertrechos, Municiones y de mas que en las Caxas Reales de esta America se administran pertenecientes a la Real Hacienda y a Depositos.»

En el segundo punto reconocía que el incumplimiento sistemático de las Instrucciones dadas por el anterior Contador General, Landazuri en 1766, para la elaboración de los tanteos, era debido «a la falta de exactitud del método anterior (cargo y data) en las reglas y modo de formar los asientos diarios, ...» Hecho que provocó multitud de defectos e informalidades, así decía:

«..., pues si se reflexiona que estos se extendian y debian hacerse por las partidas de los libros, esta claro que nunca podían salir completos, por que las cuentas y los asientos de los libros no contenían ni demostravan las distribuciones de los valores adeudados, y datas por sus clases, ni los efectos y especies que debían componer la completa cuenta anual de la administración y tesoreria de las Caxas."

En su tercer punto, ponía de manifiesto la inoperancia de la instrucción de septiembre de 1767, acerca de cómo se debía llevar a cabo la ordenación de las cuentas por parte de los Oficiales Reales ya que muchas de las que se remitían a la Contaduría General de Indias hasta 1781, no cumplían con las reglas que se establecía en la misma. Puntualizaba:

«Se vera si se cotexan las ordenaciones de unas caxas con las de otras, no solo no estan iguales aun en su formación, sin que tampoco estan uniformes en muchas de sus partes esenciales. Se vera que 
en unas de ellas no hay deudas pendientes, sin embargo de que ninguna Caxa ni Administracion de Rentas dexa de tenerlas.»

En cuanto al nuevo método de partida doble, reconocía las siguientes ventajas:

- La facilidad en cuanto a la implantación del nuevo arte en las Caxas y Administraciones principales, según sus palabras (40):

"A excepción de tres ó cuatro de ellas en unas por la absoluta ineptitud de sus ministros en materia de cuenta y razón, así del antiguo, como del nuevo método; y en otras por malicia, para tener la proporción injusta de confundir, y ocultar la mala versacion, y descubiertos en que se hallaban, como los Oficiale Reales del Cuzco, que por tan enorme delito perdieron los destinos."

- Impedimento de ocultar y negociar con los caudales del Rey.

- Claridad, exactitud y brevedad en la formación de asientos diarios, y la facilidad de poder presentar las cuentas al Tribunal, con todas las formalidades y requisitos que exigían las leyes.

- Ahorro de empleados.

De este modo vemos cómo todos los funcionarios que habían emitido informes, eran partidarios en mantener la aplicación de la partida doble y coincidían en la imposibilidad de cortar las cuentas a mitad de año y la dificultad existente para adaptar las mejoras que se añadieron al método de cargo y data, mediante la Real Orden de 25 de octubre de 1787.

Sin embargo, no faltaron opositores que opinaron en contra del nuevo método, entre ellos se encontraban D. Manuel del Campo (Oficial Real de la Caja) y los Marqueses de San Felipe y Lara (Contadores del Tribunal de Cuientas) (41). A pesar de ello, De Croix intentó restar importancia a la opinión negativa de sus oponentes, basándose para ello en la falta de fundamento y de reflexión en lo relativo al nuevo método (partida doble) y por la probada incapacidad e inhabilidad, que habían demostrado, tanto en el método antiguo como en el método nuevo. A su juicio (42):

(40) A.G.I. Sección Indiferente General, legajo 1712. Carta del Caballero De Croix a D. Antonio Valdés.

(41) Los Marqueses de San Felipe y Lara enviaron un primer informe donde resaltaban la claridad, exactitud y brevedad con que se realizaban los asientos así como los cortes y tanteos al fin de año; y señalando el posible ahorro de empleados, se retractaba en un segundo informe exponiendo que no había glosado y juzgado todavía ninguna cuenta de las presentadas por el nuevo método. En vista de esta situación De Croix afirma que fue inducido así como sus compañeros "Lara y Campo" por algunos de sus empleados. A.G.I. Sección Indiferente General, 1712.

(42) A.G.I. Sección Indiferente General, legajo 1712. 
«No podía pues en justicia aquietar mi cuidado, ni fiar el éxito de asunto tan grave sobre unas opiniones tan débiles é infundadas, y más quando por el conocimiento práctico que tengo, sé que éstos tres sugetos, sin embargo de los Empleos que obtienen, y tiempo que han servido, carecen en lo absoluto de los principios, é inteligencia necesaria para comprender el nuevo, y antiguo método, y aun para executar el menor asiento de las Partidas de Cargo y Data, y juzgar si están incompletas, ó arregladas á las leyes. Así lo persuade con la mayor evidencia, por lo que hace al Oficial Real Campo, que debía ser y se le contempla el más instruido de los tres, el hecho constante de los repetidos descubiertos que han ocurrido en estas Caxas en los Cortes, y Tanteos particulares y anuales...»

Sin embargo, la opinión del Virrey va más lejos sospechando que, dada la incapacidad manifiesta, los informes que habían remitido estos señores no fueron elaborados por ellos, sino por los empleados que estaban a su cargo, argumentando que éstos obtenían unas ganancias complementarias, fruto del desorden y caos que había en las cuentas, en la revisión y ordenación de las mismas cuando venían defectuosas.

De Croix, conforme a esta situación, ignoró el informe de estos señores, indicando el escaso interés que tenían muchos de ellos, en la reforma, ya que con la aplicación del nuevo método se suprimiría la confusión y desorden existentes, que les facilitaba unas injustas ganancias en la revisión de las cuentas, y también la utilidad de la formación de las Ordenaciones, cuando venían defectuosas o era forzoso duplicarlas para remitir a la Contaduría General de Indias, realizando estas tareas. Lo que expresaba con las siguientes palabras:

«Las excesivas cantidades que percibían por esta causa es facil que se comprenda por las certificaciones insertas en el Expediente; pues contrayendose éstas solamente á lo que há gastado la Real Hacienda por la formación de algunas Cuentas, Copias ó Duplicados desde el año de 1775 hasta el proxîmo pasado de 1788 (43), porque los Ministros obligados á su presentación o pago no exîstian, o se

(43) El 9 de diciembre de 1788, el Caballero De Croix pide tanto a la Real Aduana como a la Caja Matriz, una relación puntual de las cantidades que se han satisfecho de los fondos de la Real Hacienda en cada uno de los años desde el 1 de enero de 1775 hasta la fecha, por ordenaciones de cuentas y por la realización de Duplicados. El 13 de diciembre, José Joaquín de Arrese, perteneciente a la Real Aduana, le envía la relación formada por años, que sumaba un total de 10.406,3. El 11 de diciembre de 1788, Diego Sáenz de Ayala y Manuel del Campo, funcionarios de la Caja Real, contestaban con otra relación a semejanza de la primera que sumaba un total de 16.156,4. Toda esta información se agregó al expediente de Partida Doble y se enviaba a los fiscales. A.G.I. Sección Indiferente General, legajo 1712. 
hallavan en insolvencia, se ve que asciende á la suma de veinte y seis mil pesos ¿Y si esta cantidad há satisfecho la Real Hacienda qual será la que hayan pagado los Interesados en el propio tiempo?»

Con estas pruebas aportadas por De Croix se ponía de manifiesto un nuevo aspecto: el interés que tenían los subalternos en que no saliera adelante el nuevo método ya que la claridad, ordenación y fiabilidad que se imponía con él, les hacía perder una cantidad sustancial debido a este tipo de tareas. Estaba claro, de esta forma, que uno de los principales inconvenientes que tuvo la implantación de la partida doble, eran las propias ventajas que emanaban del propio método.

No contento aún, y entendiendo que se trataba de un tema de gran importancia, pensó que si veían con sus propios ojos, sería más fácil emitir una opinión sobre el nuevo método y así lo hizo. El 30 de diciembre de 1788, en Lima, el Virrey enviaba un oficio al Marqués de San Felipe, en el que le ordenaba que asistiese junto con los Contadores de Resultas D. Miguel Salvi, D. Santiago Leuro, D. Joaquín Bonet, y D. Juan Ignacio Vidaurre, al corte y tanteo de las Reales Cajas de la capital de Lima, que se iba a realizar el primer día útil de enero del año siguiente. $\mathrm{Y}$ que, de todo ello, informaran de forma independiente, sobre el método de la Partida Doble. Igualmente, se le ordenaba que comunicara al Marqués de Lara que actuase de la misma forma, pero en la Real Aduana, y con los Contadores de Resultas D. Juan Domingo Ordozgoyti y D. Diego de la Vega.

El 19 de enero es completado el informe de los antes nombrados y el 22 de enero se envía al Tribunal (44). Informe del que hemos extraído las opiniones más significativos de los mencionados contadores, que exponemos a continuación:

Diego de la Vega: remitía su informe el 3 de enero de 1789. Cuya opinión se puede sintetizar en el siguiente párrafo:

«..., como por los efectos nada equivocos que he reconocido en el uso de esta practica - haciendo referencia a la Partida Doble-, sere siempre apologista de la seguridad puntualidad, y exactitud infalible de un metodo tan fino; como zeloso, si los ministros y encargados en lós deberes de su obligación concurren a llevarlo con la inteligencia, empeño y eficacia que han acreditado lo de la Real Aduana. Tal ha sido su dedicación y vigílancia con la cuienta del proximo año de 1788 , que en el dia de la actuacion se pudo expedir el corte, Imbentario, y Tanteo en el termino de dos horas, ....»

(44) A.G.I. Sección Indiferente General 1712, expediente n. 371. 
Juan Domingo de Ordogoyti: que enviaba su informe el 8 de enero de 1789, reconocía:

«..., pero en la operación de esta clase a que intervenía en el citado dia 2 de enero del año 88, como en las mensuales siguientes, y la que acava de executarse Vs he visto con particular complacencia la puntualidad, claridad y brevedad con que se ha hecho esta diligencia llenando completamente quanto por unos consumados conocimientos de su importancia, asi para cerrar la anterior cuenta, como para abrir la subcesiva, ...»

\section{Y continuaba:}

«en mi entender su establecimiento en las oficinas de la Real Hacienda es de la mayor importancia, y vitalidad en seguro de los Reales intereses, y más particularmente en la Real Administración de esta capital, digolo así por que habiendo estado a mi cargo ultimamente la glosa, y fenecimiento de sus cuentas; he visto, no hay una de las presentadas desde su establecimiento en el año 74, hasta el de 82 , en que se halle una puntual constancia del devido cobrar en el año de la cuenta asi por sus productos, como por los restos de años anteriores, tocando casi imposible puntualizar̀ perfectamente tan esencial e importante requisito, ...»

Juan Ignacio de Vidaurre aclaraba, antes de comenzar su informe, no haber revisado en el Tribunal cuenta alguna llevadas por el nuevo método de Partida Doble; y que tenía escasos conocimientos de dicho arte. De todos los documentos vistos, hasta ahora, este es el que más profundi$\mathrm{za}$, confrontando el antiguo con el nuevo método, deteniéndose en cuestiones importantes como las Existencias y Deudas:

«... en obsequio de la verdad, no se puede negar que la cuenta en el nuevo método tiene el privilegio de mas delicada, segura, y tan zelosa que no admite y advierte el menor equivoco, y diferencia al tiempo de su colocación y cotejo de los saldos por su firme encadenamiento y repetición con que se habla una misma partida, esto es, en el Libro Manual, en el Mayor, y el de Caxa, pidiendo todas ellas inexcusablemente tres asientos, algunas quatro, y cinco o mas, según la naturaleza de la Especie: de forma que el error que se haya padecido en una parte, viene a descubrirse en otra con lo qual cada ramo y cosa da sus verdaderas resultas.»

«Finalmente por lo tocante a las deudas y regazos, era costumbre conforme a la ley y a la indicada instrucción en el antiguo metodo manifestarlas en el acto del tanteo los ministros responsables en una relación Jurada fuera de los Libros, con distinción de los ramos interesados, y puntual noticia de las causas que motivaron su exis- 
tencia, todo lo que se examinava por el Señor Ministro, que presidia el Tanteo, ...; y aunque por el nuevo método todos los creditos pendientes vinieron considerados en sus correspondientes cuentas corrientes en que sin disputa se afianza el mejor manejo de la Real Hacienda.»

Joaquín Bonet no entraba a comentar los puntos importantes en que radicaba la diferencia de cada método, limitándose simplemente a elogiar al nuevo método:

«El cotejo que habemos practicado de todas las cuentas y saldos en los tres libros Manual, Mayor y de Caxa, que se han advertido fielmente cerrados, y concluidos, ha acreditado en lo que permite la ligera operación de un Tanteo, no solo la delicadeza finura, y bello orden de este peregrino metodo sino tambien el laudable empeño y constante esmero que con incesantes tareas ha producido verlo todo concluido con el año bajo la particular dirección de los dos maestros.»

Santiago Leuro y Miguel Salvi: reincidían en las opiniones dadas en informes anteriores. Pero además, Leuro, aportaba un aspecto interesante, como era la importancia de que los contadores estuviesen instruidos en el manejo del nuevo método, en el asentar y trasladar las partidas de un libro a otro, y conseguir una uniformidad, de lo contrario esto causaría discordancia y por tanto demora.

Todos los documentos pasaron a manos de los Fiscales: Gorbea, fiscal de lo Civil, y Esteban Martín Balas y Fernández, fiscal de lo Criminal. Si bien el primero se quejaba de que los informes que habían llegado a sus manos no profundizaban en el tema en cuestión calificándolos de opiniones generales; no le faltaban, sin embargo, elogios para el nuevo método, donde ponía de manifiesto la transparencia de que gozaría la contabilidad de cara a los Tribunales de Cuentas:

"Lo que tiene de nuevo es haver puesto en planta y reducido a practica por medio de una feliz convinacion y profundo estudio, lo que siempre han deseado las Leyes y nunca han podido conseguir hasta aquí, es decir haver dado un Arte de llevar los asientos en los libros de Real Hacienda con tal claridad y exactitud y distinción que sin aumentar trabajo, antes bien disminuyendolo se consigue una preparación tan clara y fundamento tan solido al juicio que bá a exercer el Tribunal de Cuentas que los Jueces tienen a la vista perfecta y caval razón no solo del estado del Erario en el dinero existente en alhajas y efectos en sus creditos activos y pasivos, en sus cargos y gastos ordinarios y extraordinarios, sino tambien quales son sus ramos, sus productos y pensiones sacando por último de 
estos conocimientos firme concepto de la fidelidad, vigilancia y omisiones de los ministros de la Real Hacienda.»

"La esencia y caracter substancial del arte de Partida Doble consiste en sugetar a los asientos de la cuenta diaria tanto las materias que se reciben en efectivo como sus equivalentes en resguardos y obligaciones de credito, y en aplicarlas desde luego a aquellos ramos donde proceden, uniendo en el acto mismo del asiento las dos cosas inseparables, que con la materia, y el Dueño de ella, y con la misma proporción en la salida aumentando una y disminuyendo otra.»

Los fiscales, para terminar, recomendaban que un importante asunto como este debía ser examinado por personas con conocimiento en la materia, exponiendo las reglas, formación de tanteos, y representando casos prácticos para la mejor comprensión de ambos métodos, así como la posible puesta en práctica de la Real Orden que restablecía el método antiguo con algunas consideraciones nuevas; el problema que se planteaba era, si esos nuevos puntos se podían adaptar al método de cargo y data.

El Virrey, De Croix, siguiendo las recomendaciones de los fiscales, remitió el expediente a la Junta Superior de la Real Hacienda, que se celebró el 8 de noviembre de 1789, compuesta por el Regente y el Oidor D. Melchor Santiago y Concha, tres Contadores Mayores, dos Oficiales Reales de la Real Administración, Contador de Aduana, dos comisionados de Partida Doble, y con asistencia de los dos fiscales, pidiendo que asistiesen a ella todos los Ministros que habían informado y explicar, mediante una demostración práctica, los defectos y faltas del método anterior; y la claridad, ahorro de trabajo, seguridad, sencillez de la partida doble, tal y como puntualizaban en sus informes Uralde, Arreze, Sáenz de Ayala, Gálvez, Oyarzaval, y los fiscales.

En tal Junta no sólo se llegaron a mostrar las diferencias entre un método y otro, sino también se desvelaron las grandes ventajas que podría tener a favor de la Real Hacienda y del público en general, si se mantuviese la aplicación del nuevo método. Clarificando las posturas del Regente y Oidor a la vista de las demostraciones tan manifiestas y evidentes de las reflexiones, o comprobantes. Quedando patente, al mismo tiempo, la imposibilidad de adaptar o incluir, en el método anterior, según se llevaban los libros y cuenta, los Adeudos, los Efectos, las Especies y los Tanteos mensuales que prevenía la expresada R. Orden de 25 de octubre.

En dicha Junta se otorgó la oportunidad a Campos y Lara, para que explicasen las razones de su oposición y realizasen una propuesta para poder llevar en el antiguo método las expresadas partes - deudas, efectos 
y Especies-, que consideraban esenciales para que no provocara desorden y confusión. No contestaron, ni dieron la más leve razón, ni sobre este, ni sobre los demás puntos controvertidos, incluso se le ofreció la posibilidad de que plantearan un modelo para poder aplicar la Real Orden de 25 de octubre de 1787, de manera que si lo hacían estaban dispuestos a implantarlo por medio de Real Orden; éstos permanecieron en silencio y este silencio absoluto confirmaba aún más la hipótesis del Caballero De Croix, de que:

«sus votos fueron dictados por algunos subalternos, que aprovechandose de la ignorancia de estos jefes quisieron extinguir el método que les privaba de los Intereses injustos con que estaban tan bien avenidos».

La Junta, pues, con un expediente tan completo, unánimemente, acordó y resolvió la permanencia del método de cuenta y razón por Partida Doble (45), por ser la práctica tan ventajosa, útil e importante al buen servicio del Rey, y del público. Y así, conforme al dictamen de la Junta, lo mandó ejecutar el Virrey en una carta de 28 de febrero de 1789, previa comunicación al Rey.

El 18 de noviembre de 1789, el Monarca desaprobaba las disposiciones y providencias dadas por el Virrey De Croix y se le instaba a cumplir la Orden de 25 de octubre de 1787:

«..., mande observar en todas sus partes y en la comprehensión de ese Virreynato la expresada Orden de veinte y cinco de octubre de mil setecientos ochenta, y siete sin permitir se contravengan en manera alguna a lo que en ella se dispone. Prevengolo a Vu=Excelencia de su Real Orden para el devido cumplimiento.»

El 25 de marzo de 1790 el Caballero De Croix dejaba de estar al mando del Virreinato. Según nos informa Ramos Cerveró [1992, p. 24], el Virrey fue cesado de su cargo, pudiendo ser la causa todo este asunto y su manifiesta desobediencia al mandato real.

El 28 de mayo de 1790, en una consulta de los contadores mayores al sucesor de De Croix, Francisco Gil, planteaban el problema de cómo se debía realizar el cambio al método antiguo adoptando los tres puntos que recogía la R.O., solicitando, para ello, que se aplazara su aplicación hasta principios de $1791 \mathrm{y}$, de esta forma, elaborar un formulario claro que recogiese todos los puntos con detalle y así conseguir, en todas par-

(45) El Acuerdo de la Junta era la continuidad del método por Partidas Dobles, hasta que se elaborara un modelo donde se recogiese las modificaciones establecidas en la Real Orden de 25 de octubre de 1787. 
tes, una implantación uniforme. Éste accedía y, el 5 de junio de 1790, comisionaba a D. Diego de la Vega, por sus conocimientos contables, para el arreglo de la Cuenta y Razón y formar los nuevos modelos (de cargo y data) ajustados a la Real Orden de 25 de abril de 1787.

El 27 de agosto de 1790, D. Diego de la Vega presentaba los formularios y el papel de prevenciones donde se explicaba detalladamente el nuevo modelo de Cargo y Data (46). Documentos que son aprobados y reconocidos, con todo tipo de elogios por parte del Tribunal (4 de septiembre de 1790).

El 9 de septiembre de 1790 se convocaba a los Ministros de la Real Hacienda y al Administrador y Contador de la Real Aduana, con sus respectivos oficiales mayores, a fin de instruir a todos en el método de cuenta y razón propuesto por Diego de la Vega y de esta forma ver los posibles problemas existentes y darles la solución correcta. Desde el principio manifestó su oposición al modelo el Oficial Real Don Manuel del Villar, solicitando a Joaquín Bonet un informe del Tribunal a tres rúbricas, con el simple objetivo de retrasar la implantación del método de cargo y data.

Todo este proceso, de defensa del Arte de la Partida Doble, no estuvo exento de rencillas personales. Así, es de destacar el caso singular del Contador D. Manuel Campos; el cual, sin esperar la conclusión de los informes que pidieron los fiscales y sin entrar en un razonamiento de uno y otro método, pasó un oficio al Virrey pidiendo y exigiendo el cumplimiento de la Real Orden de 25 de octubre de 1787, en suspensión. Oficio que repetiría a los pocos días exonerándose de la responsabilidad derivada de todos aquellos actos de los contadores que estaban llevando el nuevo método (47). Ninguno de los oficios fue contestado por el Virrey.

(46) Modelo que se puede consultar en la documentación del A.G.I. Sección Indiferente General, legajo 1712 .

(47) En una declaración bajo juramento que D. Juan de Oyarzabal, Contador Mayor del Tribunal de Cuentas, realizaba en la Capitanía General sobre los procedimientos del Ministro de Real Hacienda D. Manuel del Campo con respecto a los asuntos de Partida Doble; hacía referencia al segundo oficio que al parecer fue modificado posteriormente, tal y como se confirma en las siguientes declaraciones:

«Si le consta, que en el segundo, y mas descomedido oficio protextaba, que no se hacía responsable a los Descubiertos que pudiese tener la Caxa de su cargo durante el Método de Partida-Doble.

Si tiene noticia de que, habiendo yo mandado al Secretario, que me pusiese a la vista los dos oficios de D. Manuel del Campo, me los trajo, y haviendolos reconocido posteriormente, llamé al Oficial Mayor D. Fernando Garrido, y le reconvine que cómo encontrava el segundo oficio suplantado por otro en que en gran parte estaban reformados los decomedimientos. 
Por otro lado, el comportamiento y respeto que el contador mencionado mantenía hacia los restantes contadores, dejaba mucho que desear, lo que llevaría a De Croix a tomar la decisión de separar a Campos (48) de su cargo. Así se recogía en las memorias del Virrey De Croix:

"La prudencia que me agotaron los intempestivos mal acordados oficios del Contador Campo, los repetidos insultos que hacia al Comisionado para el establecimiento de la Partida Doble, y la no responsabilidad que protestaba á la falta de intereses Reales, de que se consideraba cubierto por medio de sus oficios; me la vinieron agotar otras causas y motivos reservados. En virtud de ellos y de sus antecedentes, por decreto de $1 .^{\circ}$ de abril de 789 , resolví separar á Campo de la Contaduría de esta Caja matriz con retención de su íntegro sueldo, en atención á su avanzada edad, á su confesada inhabilidad para comprender el método de Partida Doble, á la demostrada en la Real Junta cerca del método antiguo con adopción de las calidades que previene la Real orden, y en atención á su no responsabilidad tantas veces declamada: y que el Contador comisionado Don Manuel de Villar, dando las fianzas que son de ley, ocupase aquel empleo con el mismo sueldo que goza por Real merced, entre tanto que informado S. M. arbitraba lo que fuese de su soberano agrado."

Si tiene igual noticia, que noté inmediatamente la suplantación, no sólo por la diversidad del terror del Oficio, sino también por que manifestaban su alteración la tinta fresca, y la falta de doblez en el papel." A.G.I. Sección de Lima, legajo 1069.

(48) En una carta particular exponía los motivos que le obligan a separar a D. Manuel del Campo de su plaza de Contador de la Caja Real y solicitaba al Rey la concesión de su jubilación con medio sueldo:

«En este particular digo a V. E. lo mal que se hallan servidas estas Reales Caxas: el perjuicio tan considerable que recibe la Real Hacienda, de que sus ministros no sean activos, inteligentes y zelosos: la providencia, que me veo precisado a tomar, al punto que marche el navio Aquiles, de separar a $D$. $\mathrm{Ma}$ nuel Campo de su plaza de contador dexandole, por ahora con el goce de todo su sueldo: la persona que voi a nombrar, que sin gravamen de la Real Hacienda desempeñe interinamente dicha contaduria; y en fin expongo a V.E. mi dictamen en orden a que se jubile al mencionado Campo, con la mitad de su sueldo: alegando en dicha las causas y motivos que me mueven para esta determinación todo lo qual lo reproduzca én esta a V.E. esperando, que el Rey se dignàra aprobar mi providencia. Lima 31 de marzo de 1789.» A.G.I. Sección Lima; legajo 685. 
De Croix cesó de su cargo el 25 de marzo de 1790 (49) y, prácticamente un mes más tarde, en concreto el 1 de mayo de 1790 (50), se volvía a establecer el método de Cargo y Data. El Virrey de Lima, en ningún momento quiso tomar una decisión precipitada y en solitario, por eso quiso seguir el camino más fiel al servicio del Monarca, amparándose no sólo en las leyes sino también en las instituciones que resultaron implicadas en el proceso. Proceso que le llevó a adoptar una decisión colegiada en Junta de Real Hacienda que apoyó y ejecutó.

Sin embargo, De Croix debió sentirse desacreditado y dolorido al recibir la desaprobación Real de todas las medidas que había tomado en esta materia. Estado de ánimo que, posiblemente, le indujo a retirarse, tras su cese, al convento de San Pedro, hasta el 17 de abril de 1790 que embarcó de vuelta a España.

Desde Madrid escribiría una carta al monarca, donde desvela cuáles eran sus sentimientos y estado en relación con este asunto: $Y$, precisamente, queremos que sean sus propias palabras las que cierren este apartado:

«No pudiendo pues mirar sin el mayor dolor, que de un asunto en que puso tanto tanto conato, y diligencia, y en que manifestó la pureza y regularidad de sus providencias, le haya de resultar el borrón de una general desaprobación de todas ellas con descredito de su persona y Gobierno» (51).

(49) El 26 de marzo de 1790, tomaba posesión del cargo de Virrey D. Francisco Gil y Lemos. A.G.I. Sección Lima, legajo 691.

(50) A.G.I. Sección Lima, legajo 1156-A.

(51) A.G.I. Sección Indiferente General, legajo 1712. Carta de De Croix al Monarca fechada en Madrid, 31 de diciembre de 1790. 


\section{MODELO DE ORDENACIÓN DE CARGOS Y DATAS}

$A \tilde{N} O \ll X »$

AÑO $\ll+1 »$

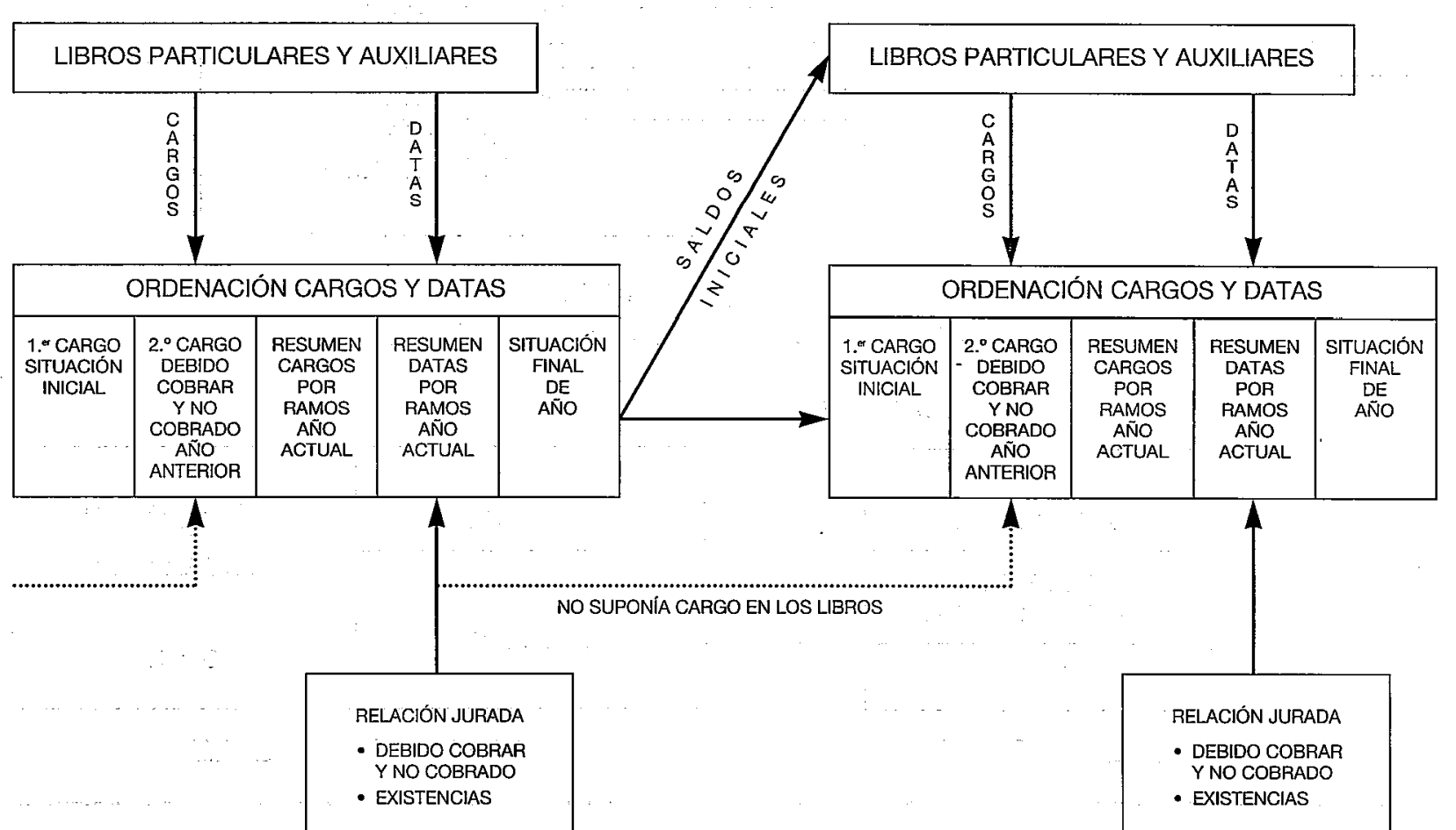




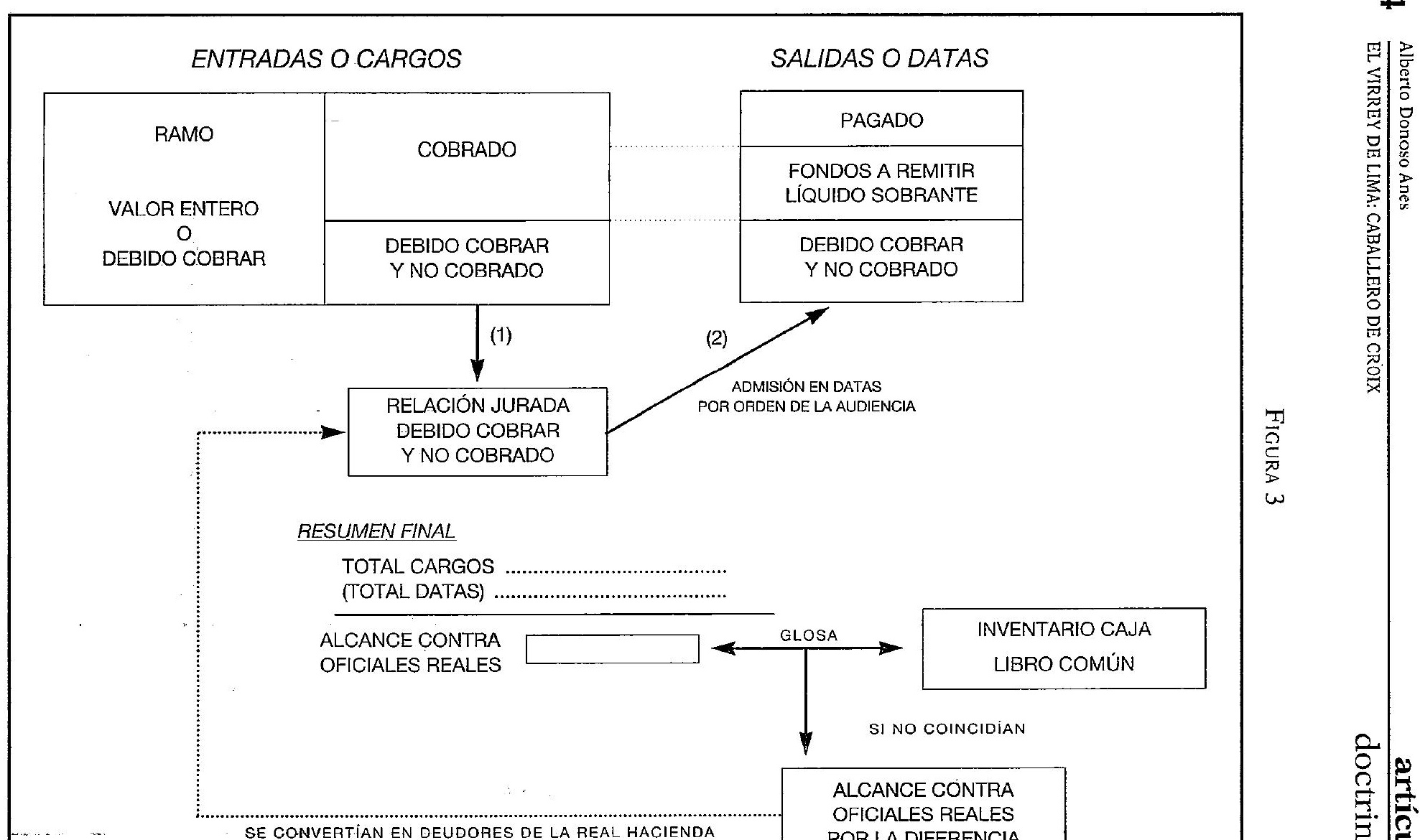




\section{BIBLIOGRAFÍA}

Bermejo Cabrero, J. L. [1982]: Estudios sobre la Administración Central Española (s. XVII y XVIII), Ed. Centro de Estudios Constitucionales, Madrid.

Bielfeld, Baron de: Instituciones Políticas, París. La edición en castellano de esta obra fue realizada por D. DOMINGO DE LA TORRE y MOLLINEDo entre 1767 y 1781. Ambos ejemplares los hemos localizado en la Biblioteca Colombina de Sevilla.

Casares, J.: Diccionario Ideológico de la Lengua Española, 1. ${ }^{\mathrm{a}}$ ed., 2." tirada, Ed. G.G., S.A., Barcelona.

Donoso A. [1997]: «Estudio histórico de un intento de reforma en la Contabilidad Pública: La aplicación del Método de la Partida Doble en las Cajas Reales de Indias (1784-1787)", Revista Española de Financiación y Contabilidad, vol. XXVI, núm. 93, pp. 1045-1089.

- [1999]: «Nuevo método de cuenta y razón para la Real Hacienda en las Indias: La Instrucción Práctica y Provisional en forma de Advertencias Comentada (27 de abril de 1787)», IX Congreso de AECA, tomo I, pp. 907-934, septiembre 1997. Publicado en la Revista Española de Financiación y Contabilidad, vol. XXVIII, núm. 101 (julio-septiembre de 1999), pp. 817-862.

Donoso, R., y Donoso A. [1998]: Presentación y estudio introductorio sobre la vida y obra de D. Sebastián de Jócano y Madaria (1738-1821), Estudio sobre la vida y obra de Sebastián de Jócano y Madaria que acompaña a la reedición de su obra que lleva por título: Disertación Crítica y Apologética del Arte de llevar Cuenta y Razón por Sebastión de Jócano y Madaria, AECA, en su serie de Estudios de Historia de la Contabilidad.

Fuentes, M. A. [1859]: Memoria de los virreyes que han gobemado el Perú, durante el tiempo del coloniaje español, tomo V, D. Teodoro De Croix, pp. 305 a 312. Librería Central de Felipe Bailly, Lima.

Jócano y MadaRIa, S. [1793]: Disertación crítica y apologética del arte de llevar la cuenta y razón contra la opinión del Barón de Bielfeld acerca del Arte en General $y$ del Método de Partidas Dobles en Particular, Madrid.

Machado Fiesco, Fco. [1780]: «Papel de Consideraciones en que se trata el Método de cuenta y razón que con arreglo a tres leyes del tít. $7 .^{\circ}$, lib. $8 .^{\circ}$ de la recopilación de las Indias conviene establecer en aquellos Dominios», Documento Manuscrito, Madrid, 20 de junio de 1780, A.G.I. Sección Indiferente General, legajo 1712.

— [1784]: «Instrucción práctica y provisional en forma de advertencias, que debe servir a todas las Caxas Reales, o Foraneas de las Indias, para el modo de llevar las cuentas de la Real Hacienda entre año, de formar Estados Mensuales y Tanteos anuales y de dar la Cuenta General en fin de cada uno como esta mandado", Madrid, 27 de abril de 1784.

Mendiburu, M. [1934]: Diccionario Histórico Biográfico del Perú, Lima, vol. VIII. 
Navarro Garcia, L. [1959]: Intendencias en Indias, Escuela de Estudios Hispanoamericanos, Sevilla.

OrTiz de LandazurI, T.: «Instrucción práctica formada por esta Contaduría General que demuestra el método, reglas y expresión con que anualmente se deberán executar los Tanteos y Cortes de Caxa en todas las de América, ... para formar los cortes y tanteos, ...», 18 de julio de 1766, aprobándose el 23 del mismo mes y ordenando su aplicación a partir del 19 de agosto de 1766.

- «Instrucción dispuesta por la Contaduría General, con el fin de instruir á los Oficiales Reales, Tesoreros, Depositarios y demás personas que perciban caudales de la Real Hacienda en al América, y que deban dar cuenta en el modo y reglas que deben observar para la ordenación de las que han de presentar desde 1 de enero de 1768 en adelante en los Tribunales de México, Lima, y Santa Fé, y otros de aquellos dominios», A.G.I. Sección Indiferente General 1712.

Ramos Cerveró, R. [1992]: «La Contabilidad en la Administración Virreinal Americana", Ponencia presentada al Encuentro de Trabajo En torno a la elaboración de una historia de la contabilidad en España, Miraflores de la Sierra. Publicado en 1996, por AECA en la serie Estudios de Historia de la Contabilidad, pp. 297- 314.

SÁnchez Bella, I: Derecho Indiano: Estudios. Tomo I: Las Visitas Generales en la América española (s. xVI y xVII), Ed. Universidad de Navarra, Pamplona, 1991.

\section{DOCUMENTACIÓN CONSULTADA}

Archivo General de INDias:

Sección Indiferente General:

legajos: 662, 989, 995, 1009, 1706, 1712.

Sección Lima:

legajos: 677, 685, 688, 691, 1069, 1156-A,

Sección de Méjico:

legajo: 320 